\title{
عدم تقادم جرائم الحرب
}

\author{
الباحث/ هممود صالح عاتي \\ باحث دكتوراه في القانون الدولي- كلية الهقوق- جاهعة عين شمس هي
}




\section{عدم تقادم جرائم الحرب}

\section{الباحث/ هممود صالح عاتي}

\section{همقدهة}

بعد ان شعر المجتمع الدولية بخطورة تلك الجرائم ولا بد من وضع نصوص قانونية صارمة تمنع سقوط تلك الجرائم بمضي المدة على ارتكابها بغية عدم افلات من مرتكبيها

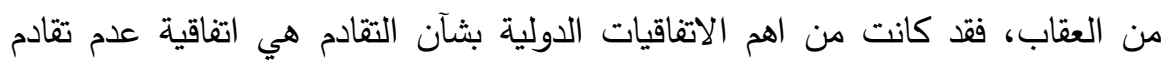

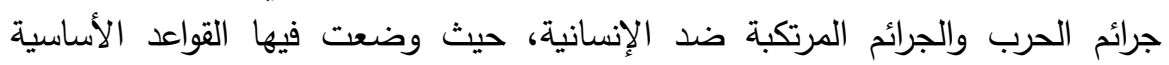
الخاصة بعدم تقادم الجرائم الدولية، وبعد ان لاحظت ضرت الجمعية العائة العامة للامم المتحدة خلو

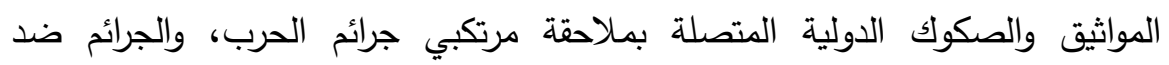
الانسانية وجرائم الابادة من النص على عدم التقادم، بعد ما اصبح تاثير تلك الجئئ الجرائم

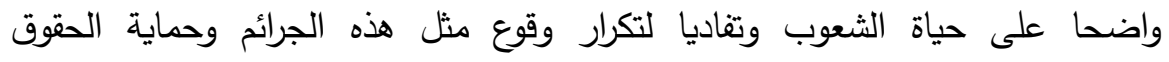
والحريات واقرارالامن والسلم الدوليين، فقد حرص المجتمع الدولي على عقد اتفاقياتية عدرم

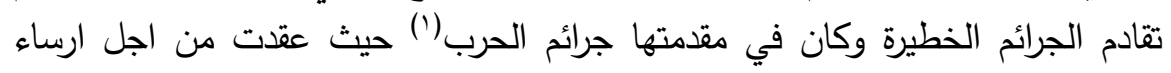

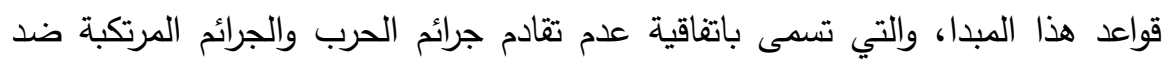

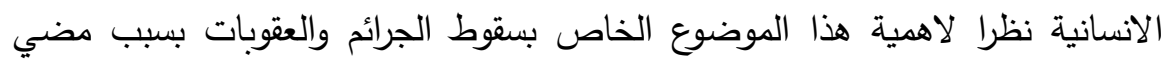

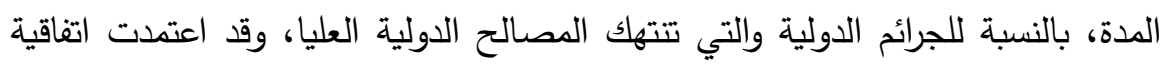

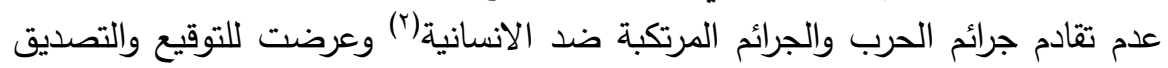

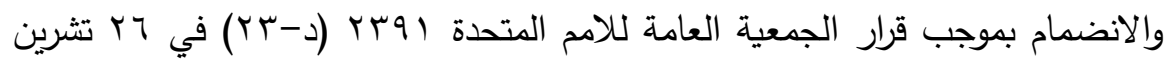

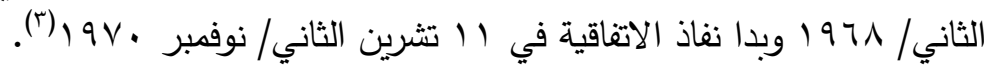

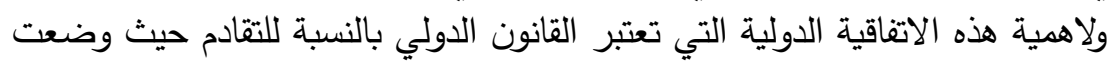

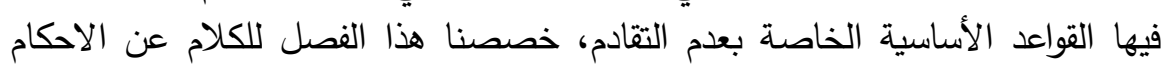

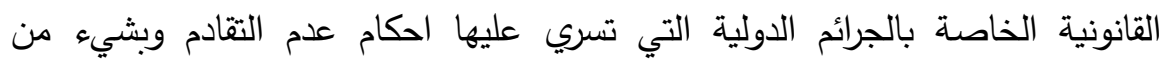

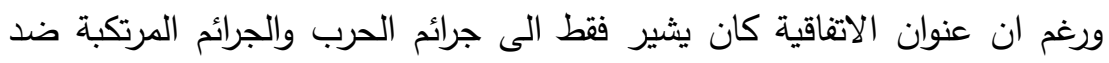
الانسانية الا ان مضمون هذه الاتفاقية، قد جاء ليثمل جرائم دولية اخرى بالاضافة الى الى

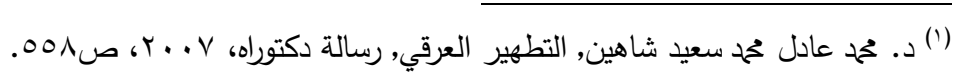

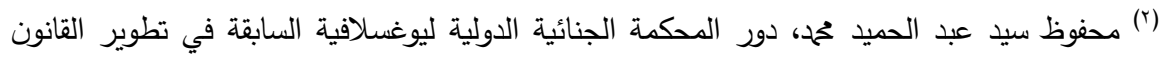

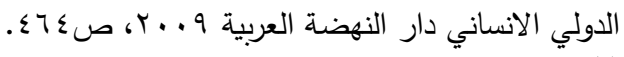

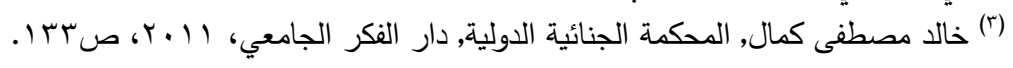

\section{$(r v \leq \varepsilon)$}


الباحث/ محمود صالح عاتي

جرائم الحرب والجرائم ضد الانسانية، حيث نصت على افعال اخرى وهي جريمة الابادة الجماعية وجريمة طرد السكان المدنيين واحتلال مناطقهم وجريمة الافعال اللاانسانية

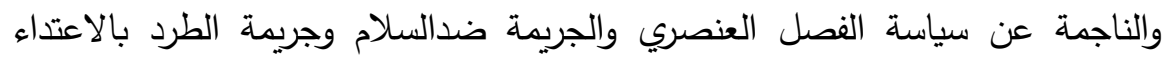
المسلح والاحتلال، لذا سنتاول هذا الفصل في اربعة مباحث الاول عن عدم تقادم جرائم الحرب والثاني عن عدم تقادم الجرائم ضد الإنسانية، والثالث عن عدم تقادم الثادئ جريمة

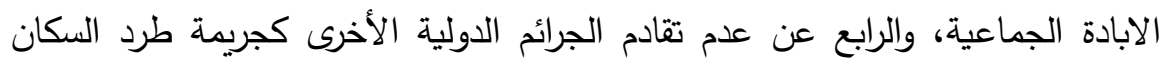

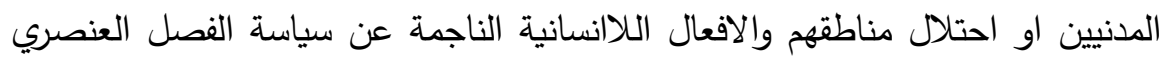
وجريمة ضد السلام مع بيان الاثار القانونية لمبدا عدم التقادم على تلك الجرائم.

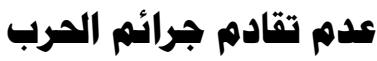

ان الحديث عن عدم تقادم جرائم الحرب الواردة في هذه الاتفاقية الدولية يستوجب

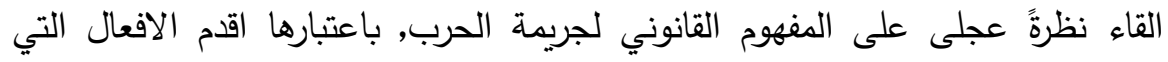

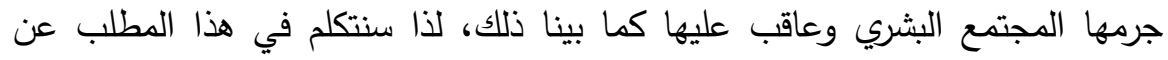

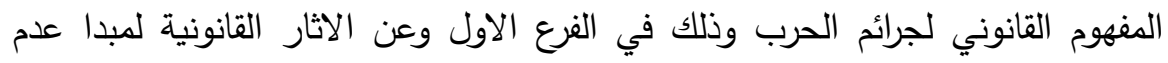

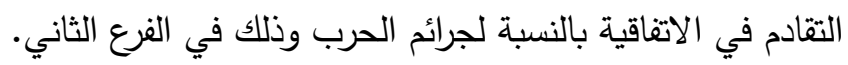

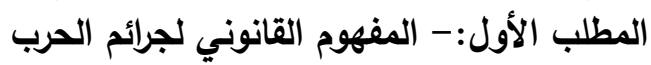

المطلب الثاني:- الاثار القانونية لمبدآ عدم التقادم على جرائم الحرب المبر

\section{الإطلاب الأول}

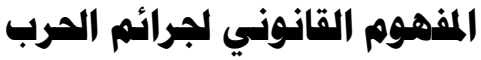

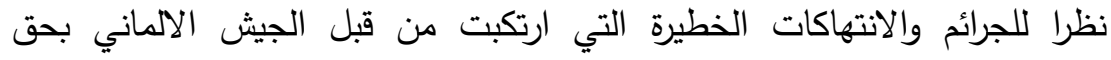

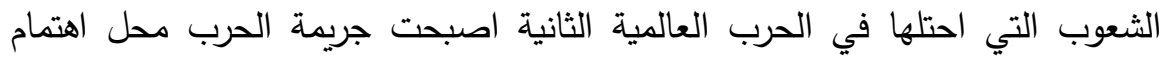

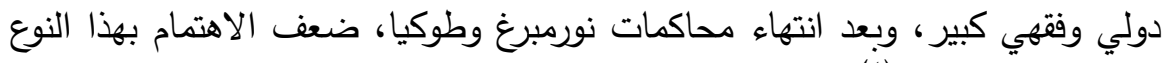

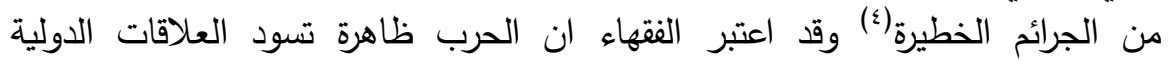

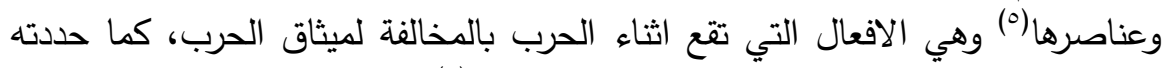

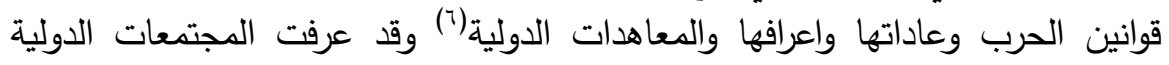
() د. مصطفى لطفي عبدالفتاح, اليات الملاحقة الجنائية في نطاق القانون الدولي الانساني, دار الفكر

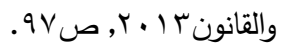

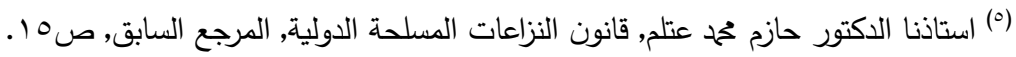

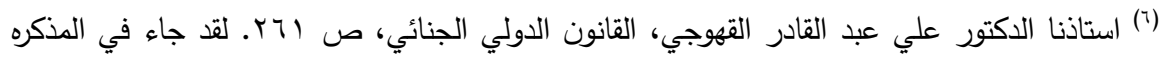
الخاصة. بتفسير الاركان الخاصه بجريمة ابعاد السكان او النقل القسري للسكان.

\section{$(r v \leq 0)$}


نوعين من الحروب الاولى الحرب المشروعة والثانية حرب العدوان اوالاعتداء وهنالك

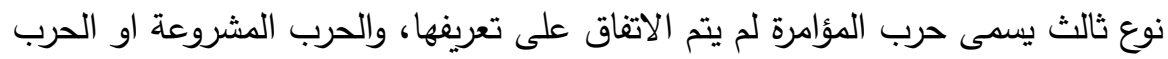

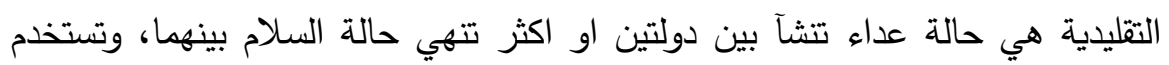

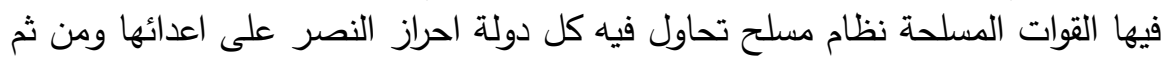

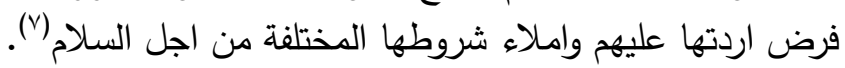
وعرفت الحرب انها حالة نظام مسلح بين الدول على اثر قطع على علاقات السلام بينهما الا ان المواثيق الدولية عرفت بعضها جريمة الحرب والاخرى اكتقت بذكر افعال

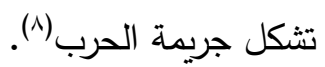
وقد عرفت المادة السادسة من لائحة محكمة نورمبرغ الحرب بانها "الاعمال التي

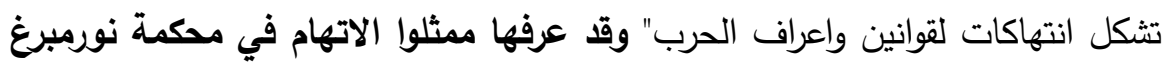

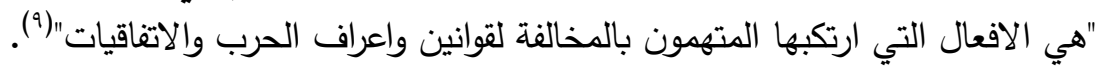
ويعتبر العرف مصدرا اساسيا لجرام الحرب التي قننت بعد ذلك في اتفاقيات لاهاي

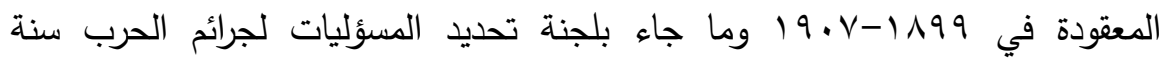

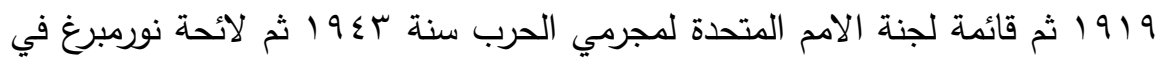

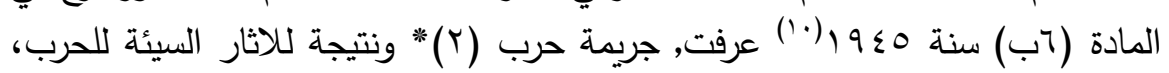
يرى بعض الفقهاء ان التعريف الواقعي لحالة الحرب تتحقق بكل قتال بين القوات

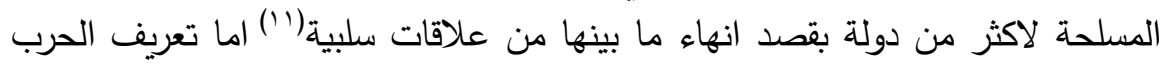
من الناحية القانونية فان حالة الحرب تستلزم صدور اعلان رسمي من جانب الدول

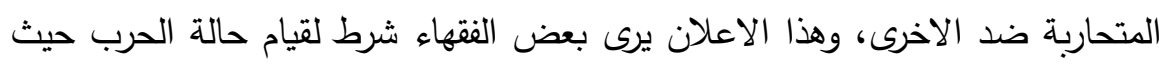

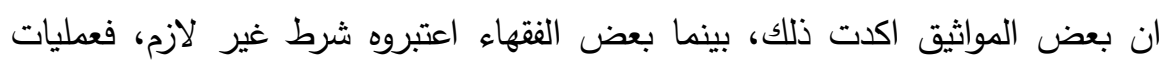
القتال دليل على قيامها وعلى هذا الاساس اعتبرت الولايات المتحدة الامريكية

$$
\begin{aligned}
& \text { (v) استاذنا الدكتور علي عبد القادر القهوجي القانون الدولي الجنائي. مرجع سابق، صه V. }
\end{aligned}
$$

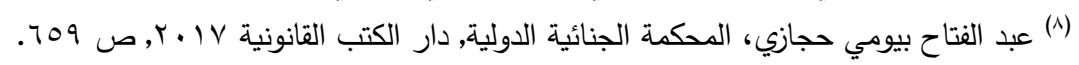

Donnedieu de Vapres- LES process de nurmerge devant ies Principes du Droit international-1947-p-507.

(·) د. عبد الواحد محم الفار, الجريمة الدولية وسلطة العقاب عليها, دار النهضة العببية 9907 , 


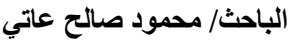

الاعتداءات الصادرة من المانيا ضدها سنة 191V كافية لقيام حالة الحرب حيث اعتبرتها قائمة, ولا يشترط لقيام حالة الحرب صفة معينة في الجاني لكي تقع جرائم

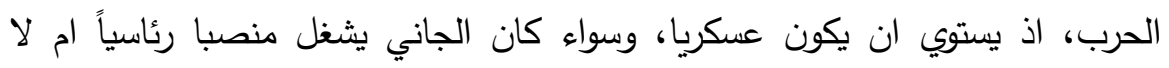

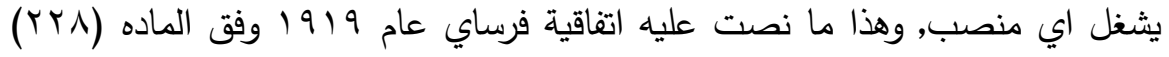
كما يستوي الامر سواء كانت حرب اعتداء اي ان الدولة لجات اليها رغم رغم عدم

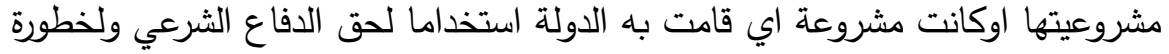
الحروب, دفعت الفلاسفة وفقهاء القانون في القرنين السابع عشر والثامن عشر امثال (جروتيوس) وفانيل وسوارز ومونتسكيو ورومو فكتورهيفً وغيرهم الى جعل الحرب الى

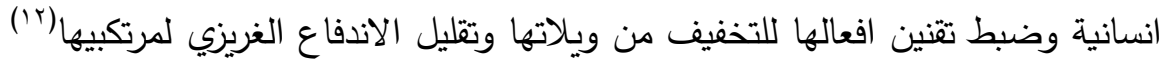

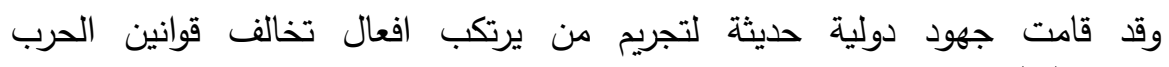

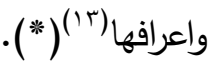
وسياسيا تستهدف الحرب كسر ارادة العدو, وفرض ارادة الطرف المنتصر يرى

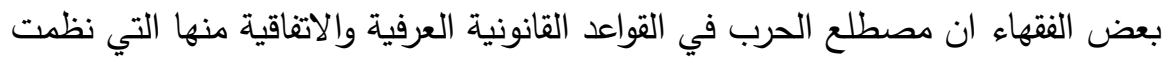

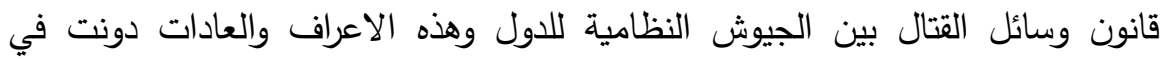

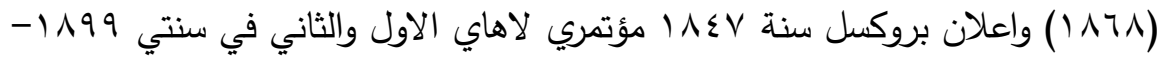

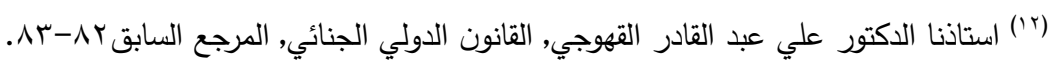

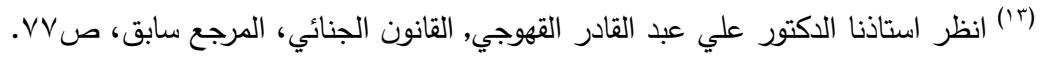

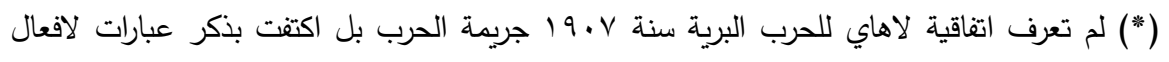

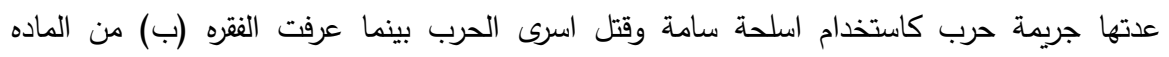

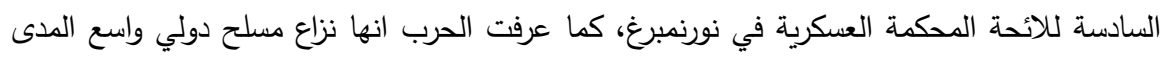

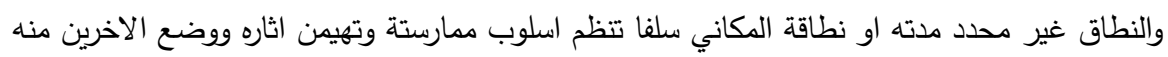
قواعد القانون الدولي يستهدف احد طرفية او كلاهما فرض ارادته على الطرف الاخر واخضاعة واملاء شروطة عليه تحقيقا لمصلحة هامة يبتغيها حال توافر نية الحرب لدية واتجاة ارادتة صراحه او ضمنا

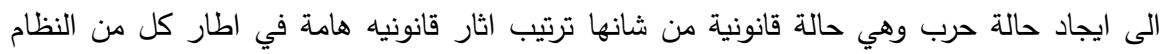

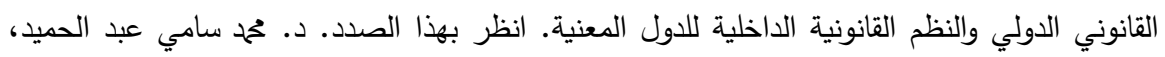

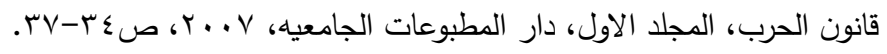

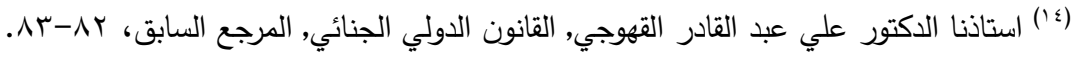

\section{$(r v \leq v)$}


وقد نص قانون المحكمة الجنائية العراقية العليا على كافة الافعال التي اعتبرتها

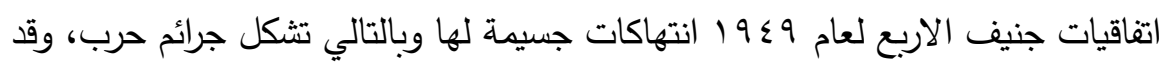

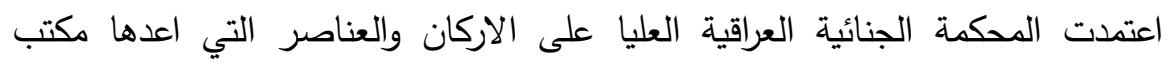

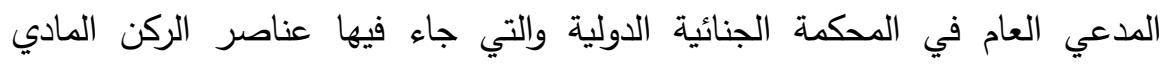
واثباتاتها وجريمة الحرب تتكون من الركن المادي والمعنوي والدولي نبين ذلك على النحو

$$
\begin{aligned}
& \text { الفرع الاول:- الركن المادي في جريمة الحرب. }
\end{aligned}
$$

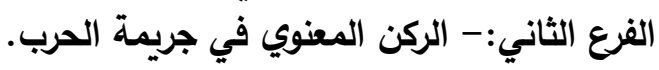

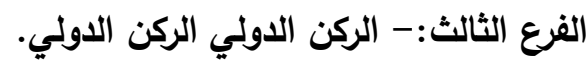

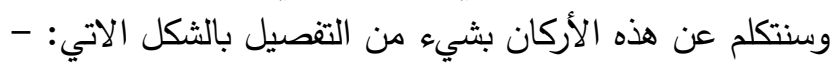

\section{الفرع الأول}

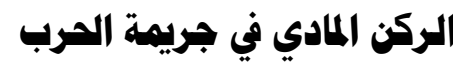

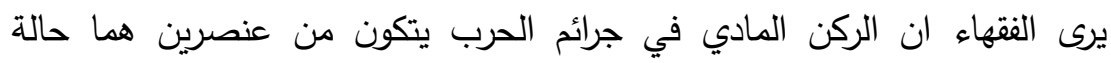

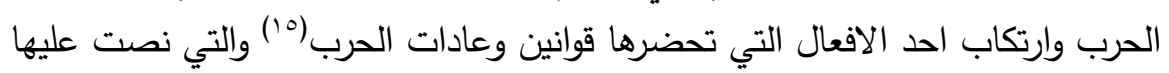
اتفاقيات جنيف لعام 9 9 1 الذا سنتناول هذين العنصرين بالثكل الاتي:

(10) نشات مبادىه في القرن السابع الميلادي والتي تسمى بمعاير الحرب العادلة والتي اطلقها الفيلسوف

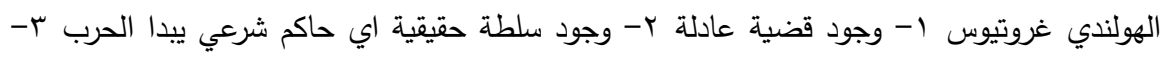

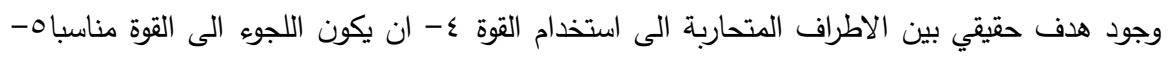

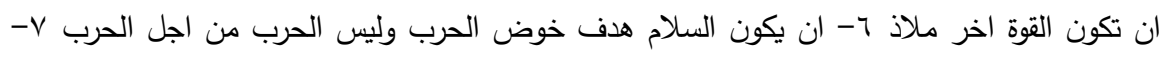

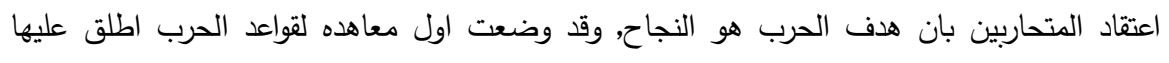

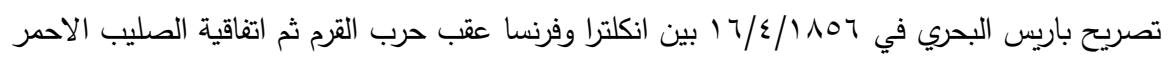

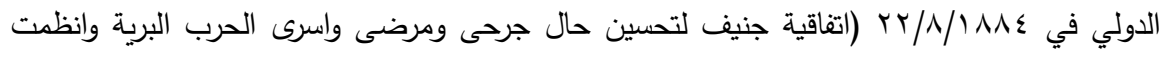

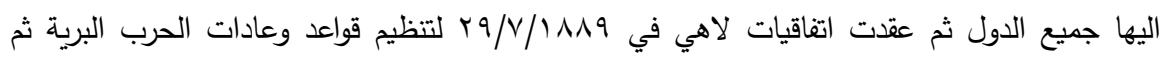

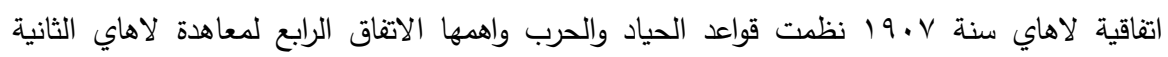

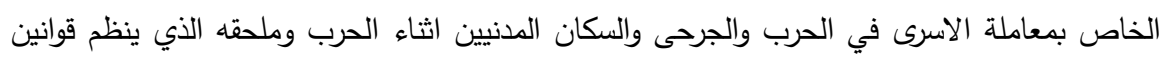

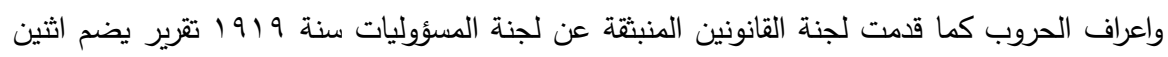

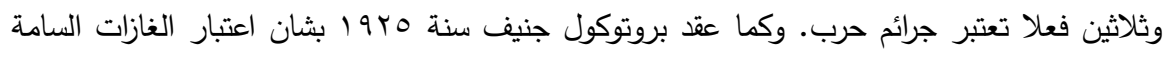

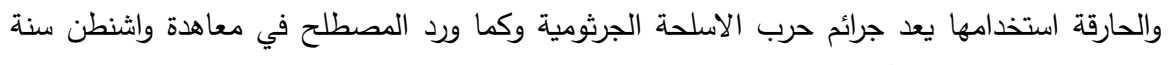

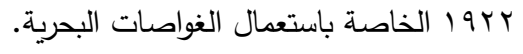

\section{$(r v \leq \Lambda)$}


ان حالة الحرب وكما بينها بعض الفقهاء تبدا مع بدا الحرب وتتتهي بنهايتها غير مرتبطة- بالضرورة ببدء استمرار او جود عمليات قتال(1') وهنالك اثار قانونية تترتب

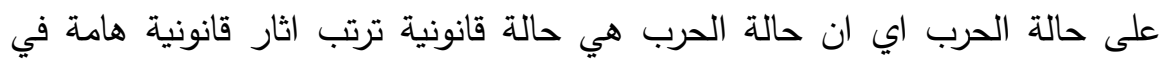

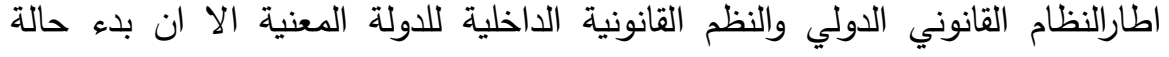
الحرب لا يعني خروج العلاقة بين اطرافها عن نطاق العلاقات التي تتظمها قواعد العانيه

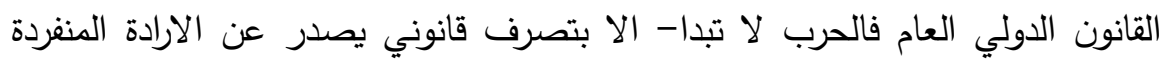

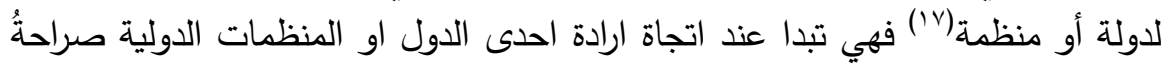

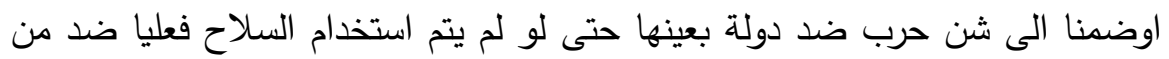

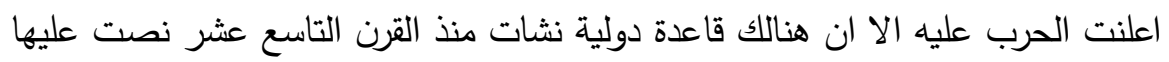

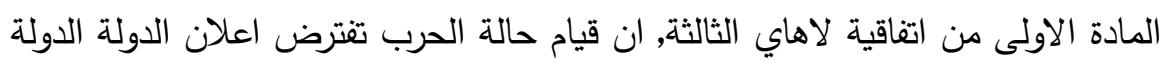

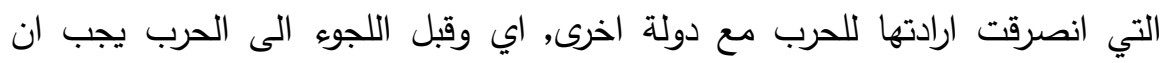
يصدر اخطار مسبق قد يكون في صورة اعلان الحرب اوبانذار نهائي باعتبار

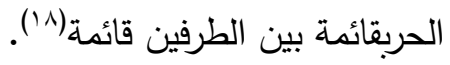

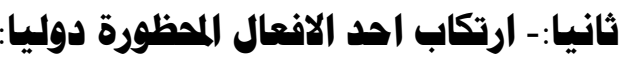

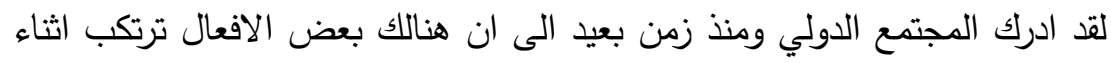

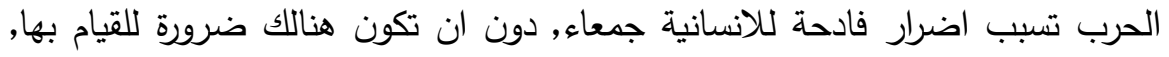

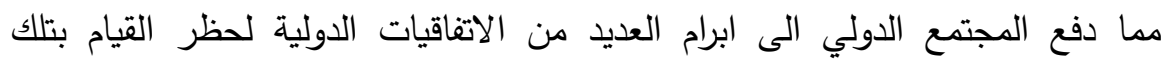

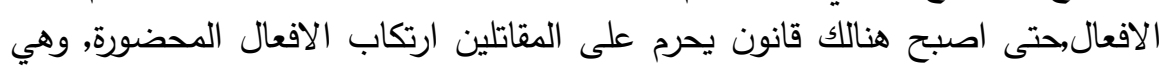

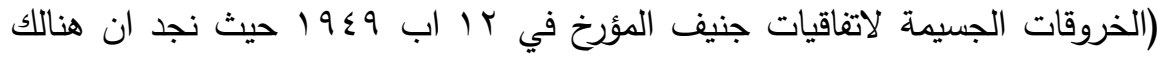

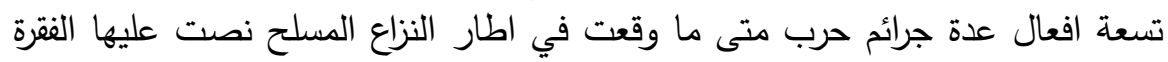

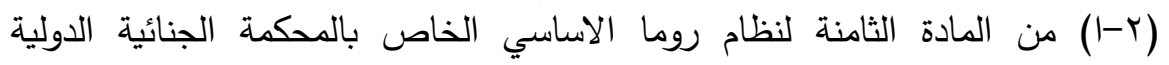

(") اكدت المحكة العسكرية لنورنمبرغ في احد قرارتها ان الحرب تعتبر غير مشروعة في القانون

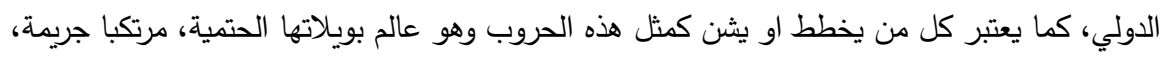

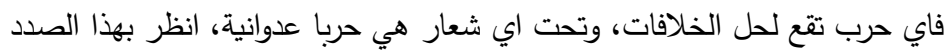
Pompe; aggressive war and international war London, 1954, p.23

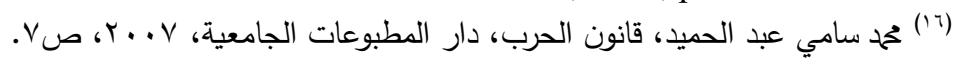

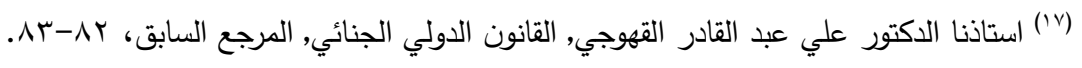

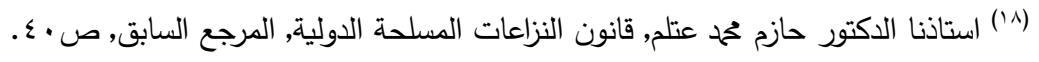


الانتهاكات الخطيرة الاخرى للقوانين والاعراف الواجبة التطبيق على المنازعات الدولية المسلحة في النطاق الثابت للقانون الدولي. الاتحئ

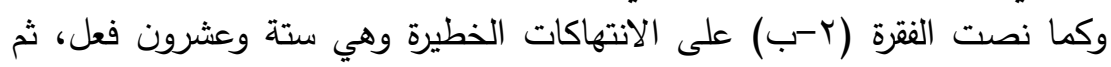

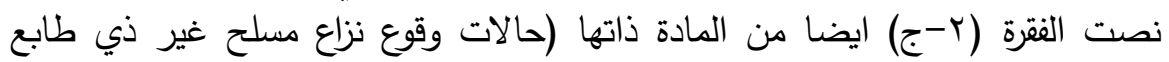

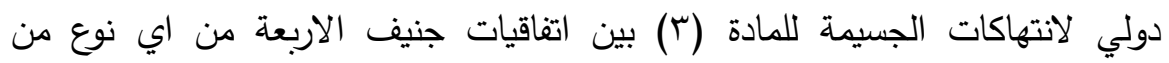

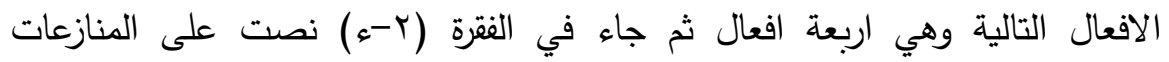

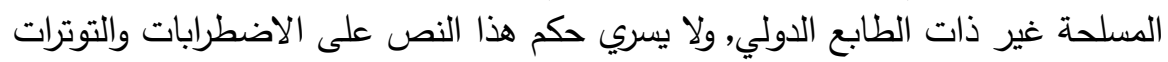

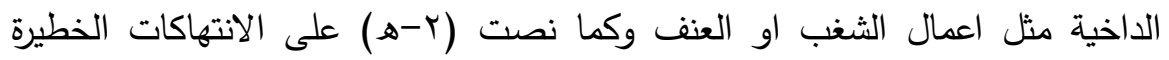

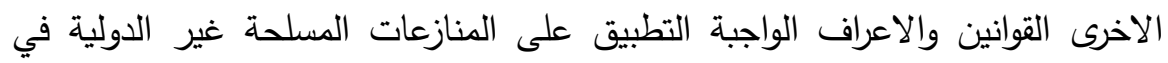

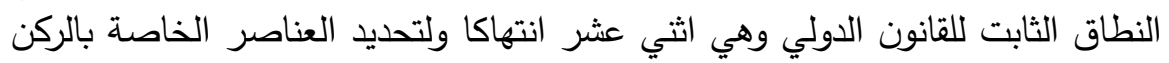

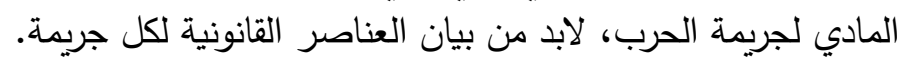

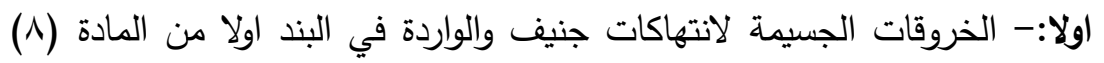

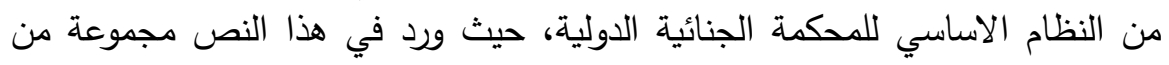

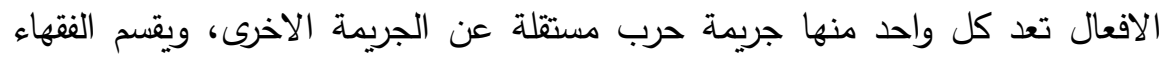

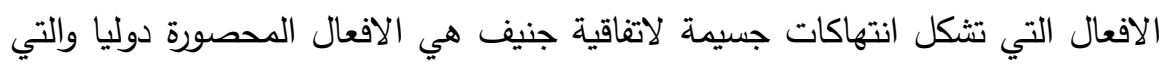

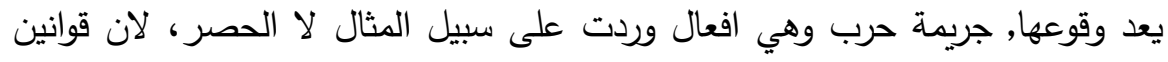
واعراف الحرب يحددها العرف الدولي. حيث يفرق الفقه بين نوعين من هذة الافعال: افعال محظورة تبعا الى وسيلة

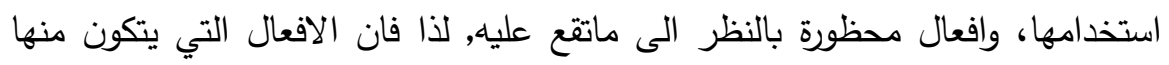

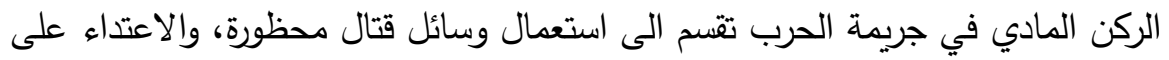

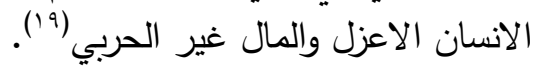

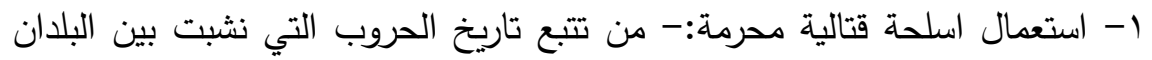

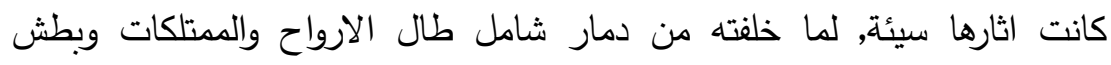

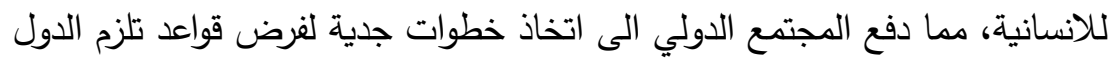

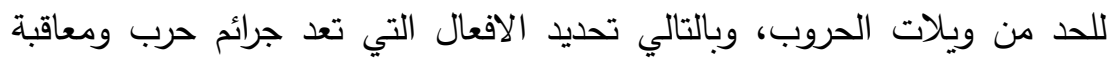

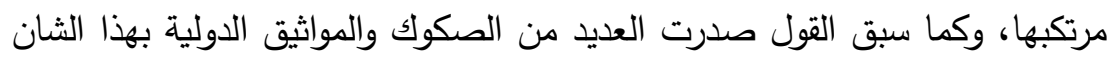

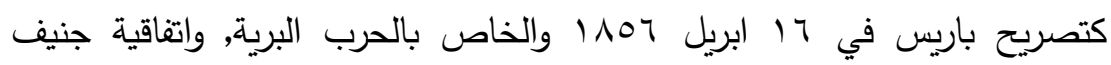

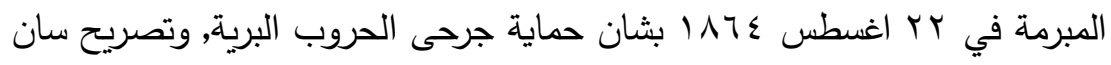

$$
\text { (9'1 استاذنا الدكتور علي عبد القادر القهوجي، القانون الدولي الجنائي، المرجع سابق، ص010-1. }
$$

$$
(\text { rvo. })
$$


الباحث/ محمود صالح عاتي

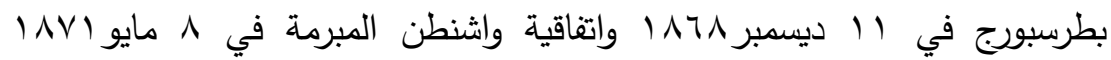

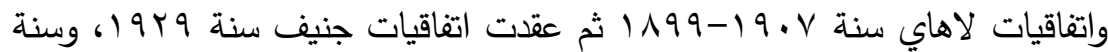

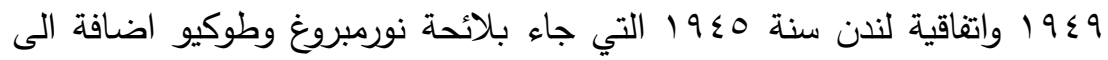

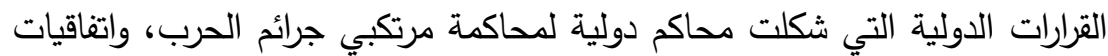

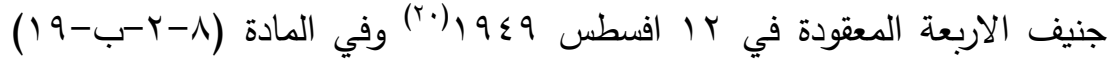
من النظام الاساسي للمحكمة الجنائية الدولية,على تحريم استخدام الرصاصات التهات التي

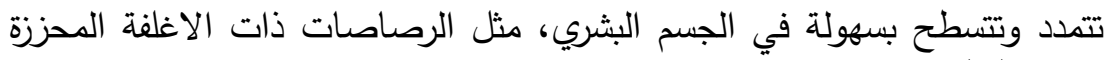
الغلاف (r)'•.

فاستخدام كل هذه الانواع جرائم حرب ويضرب الفقه امثلة على اهم تلك الاسلحة

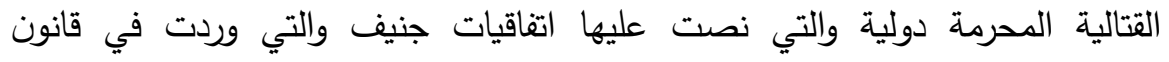

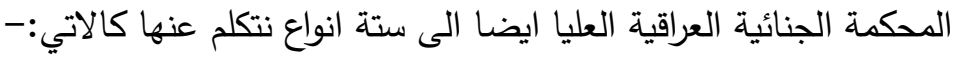

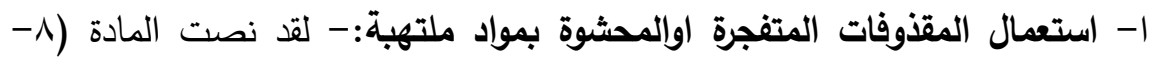

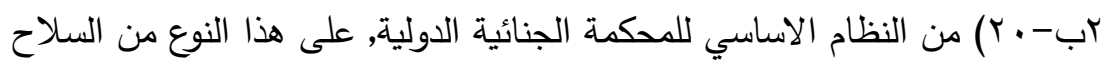
بقولها "استخدام الرصاصات التي تتمدد او تتسطح بسهولة في الجسم البشري مثل

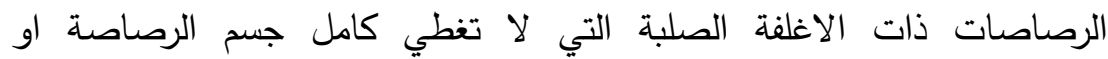
الرصاصات المحزة الغلاف".

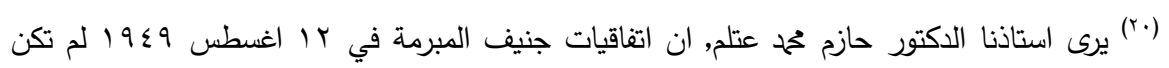

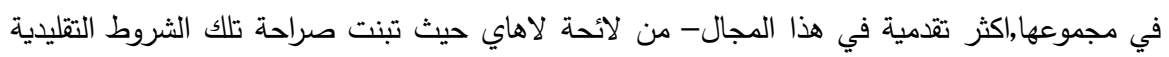

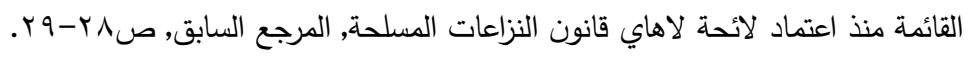

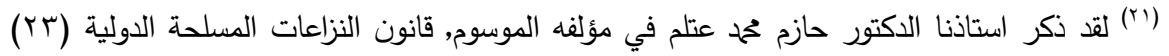

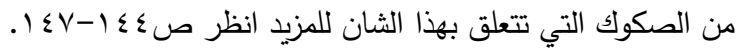

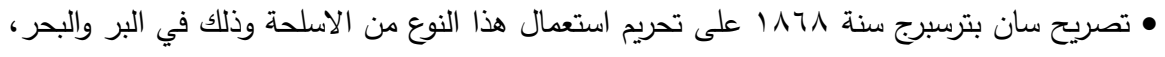

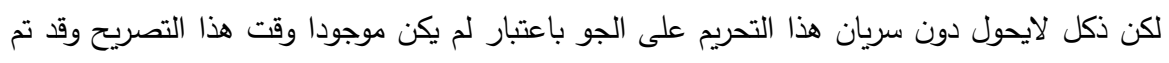

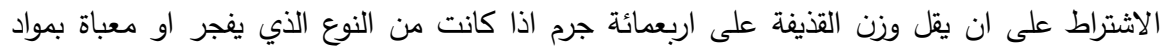

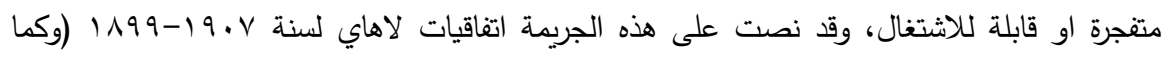

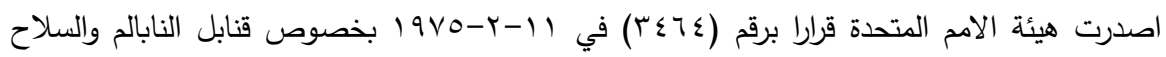

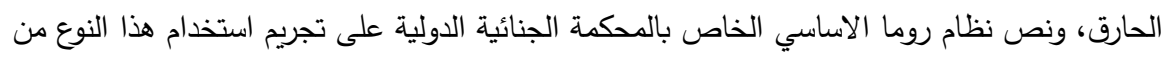

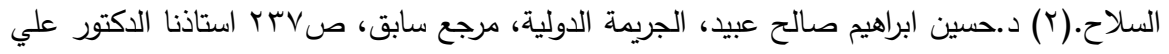

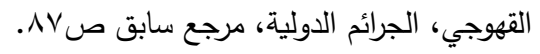

\section{$(r v 01)$}


Y- استخدام الاسلحة السامة:- لقد نص على تحريم استعمال هذا النوع من الاسلحة

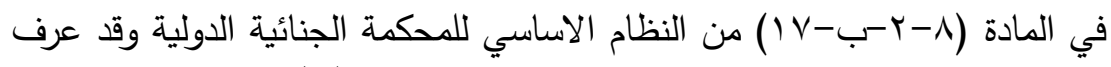

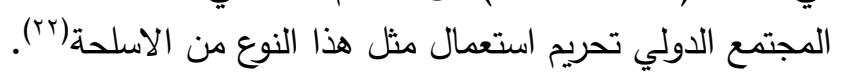

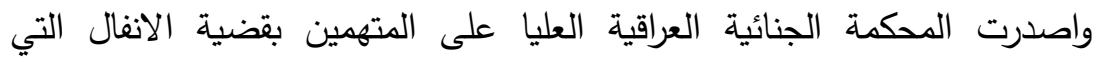
استخدم فيها الاسلحة الكيمياوية راح ضحيتها الالاف من السكان المدنيين العزل من شيوخ واطفال ونساء اضافة الى اصابتهم بامراض لا تزال اثارها باقية نتيجة لاستخدام

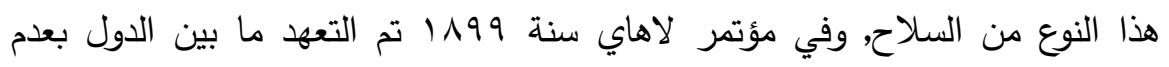

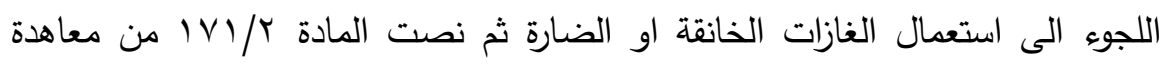

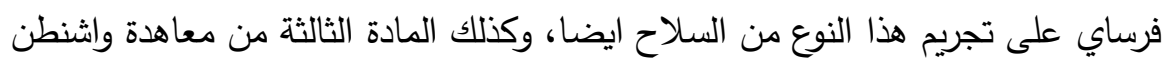

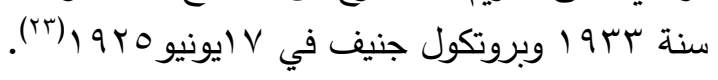

r- السلاح البولوجي والبكترولوجي او الجرثومي:- لقد نصت ندئ على تحريم استخدام

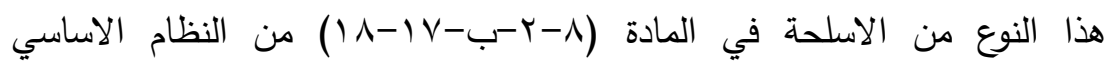

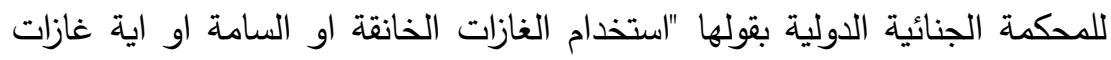

$$
\text { اخرى وكذلك اية سوائل او مواد او معدات اخرى مشابهة". }
$$

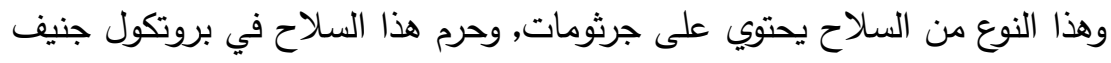

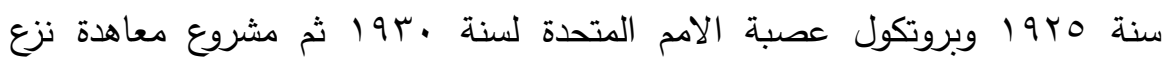

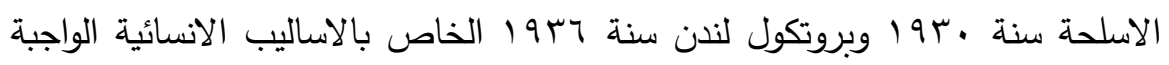

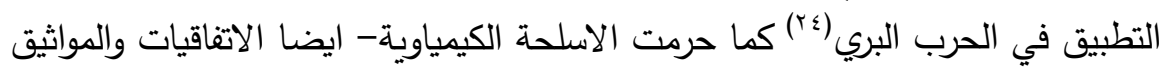
الدولية السالفة الذكر , والاسلحة الكيمياوية هي التي تصنع من مواد كيمياوية حيث انها

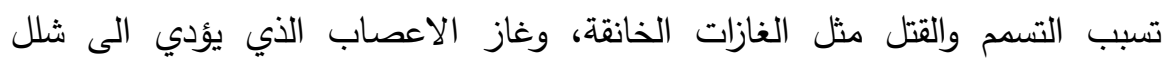

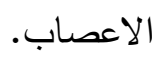

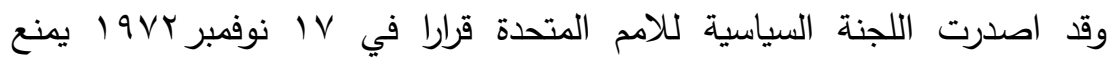

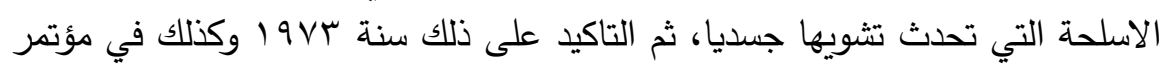

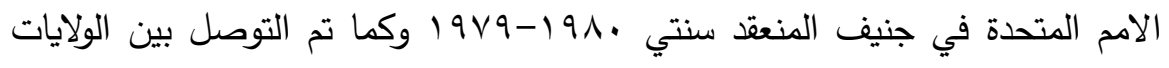

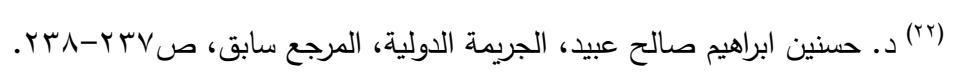

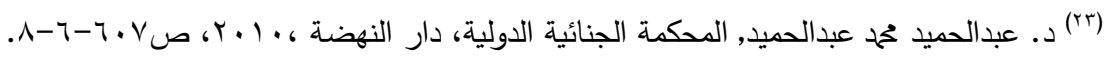

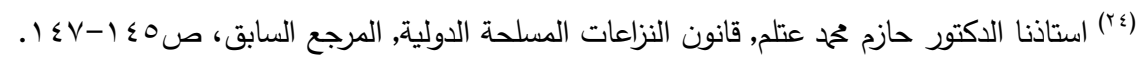

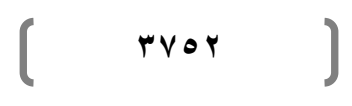




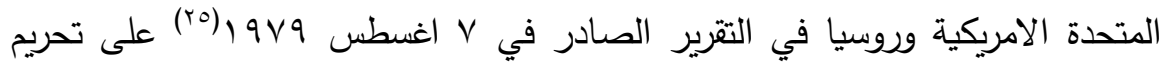
هذا النوع من السلاح, وجاء تحريم هذا النوع من الاسلحة اليضا في نظام فيكات روما الاساسي

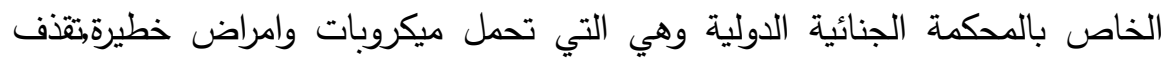
على الهدف الدقصود, فاستعمالها يؤدي الى الاصابة بامراض خطيرة، الو الئ موت الانسان

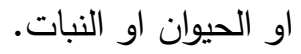

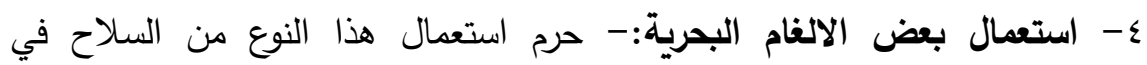

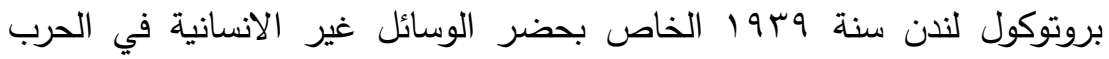

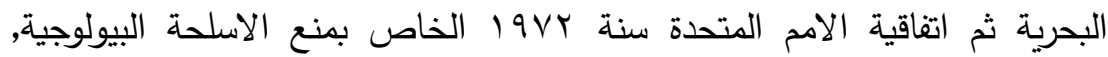

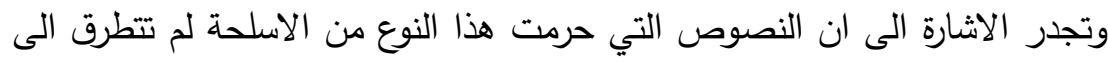

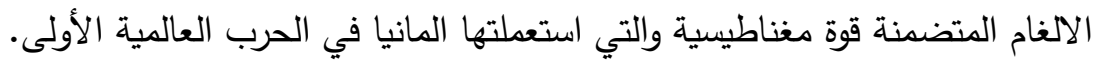

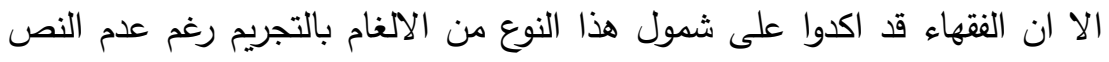

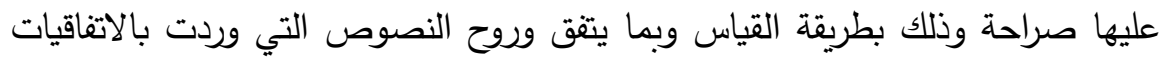

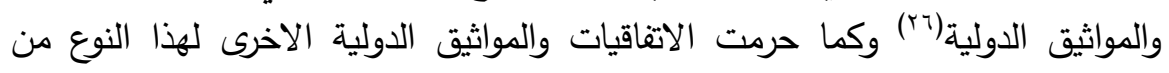

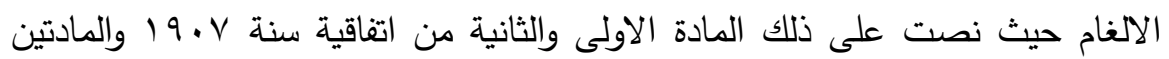

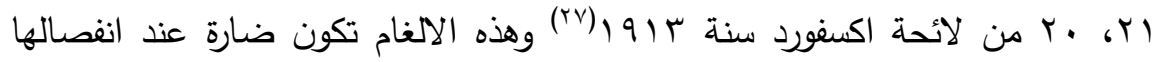

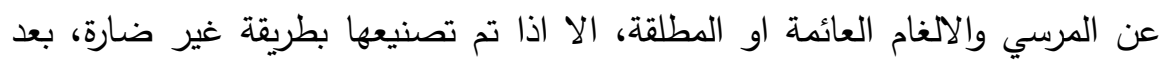

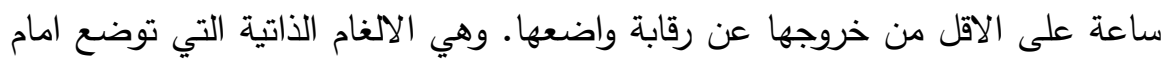

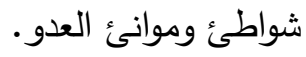
0- القيام باساليب الذاع والغش غير المشروعة:- نصت على ذلك المادة (V/ب)

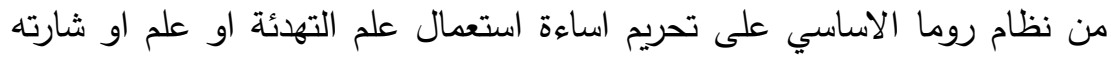

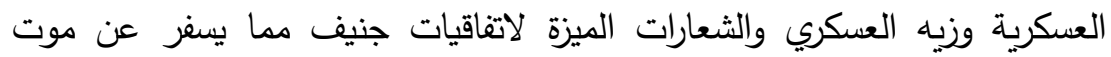

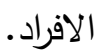
وكما قد حرمت المادة (Yrّ) من البروتوكول الاول الملحق الاول الملحق باتفاقيات

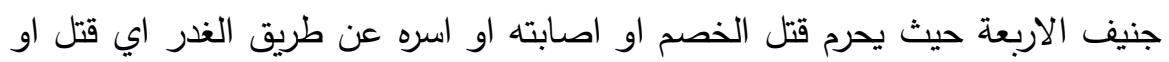

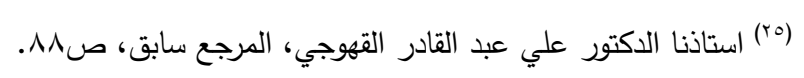

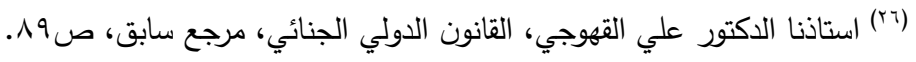

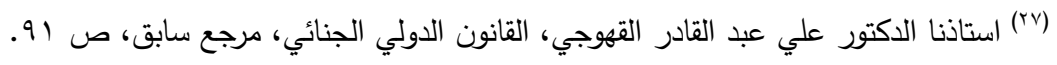

\section{( rvor)}


جرح اي من افراد دولة معادية او جيش معاد بطريقة غادرة، وبالتالي فان فكرة الحرب

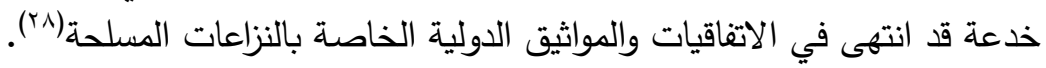

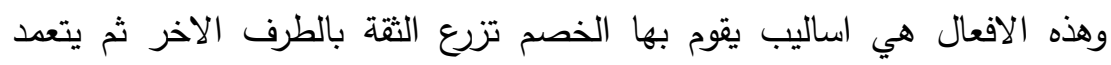

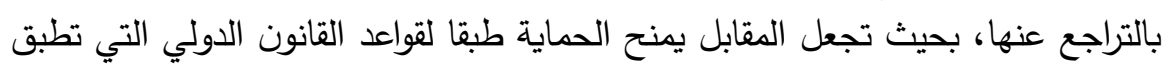

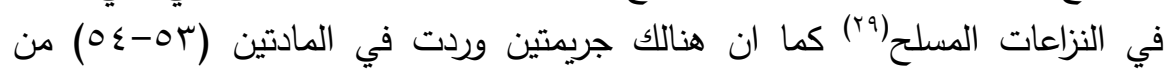
اتفاقية جنيف الاولى والمادتين (0؟-؟ ؛) من اتفاقية جنيف الثانية وهي سوء استخدام

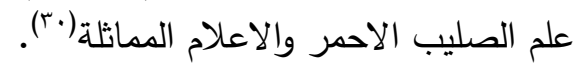
ج- السلاح النووي او الذري:- لا يخفى على احد ان السلاح الذري ينتج اضرار بالغة

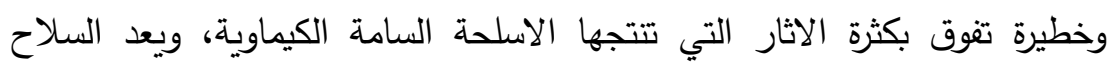

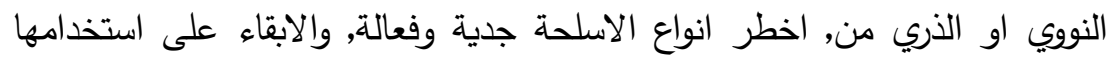

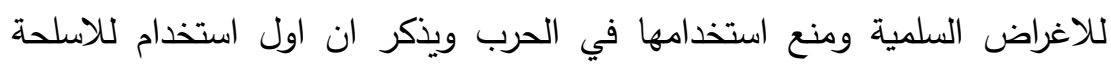
النووية في تاريخ الحروب الدولية هو سنة 9 أو في الحرب العالمية الثانية، عندما اطلقت الولايات المتحدة الامريكية القنبلة الذرية على مدينتي هيروشيما ونكازاكي في اليابان، وذلك استخداما لحقها في الدفاع الشرعي(•).

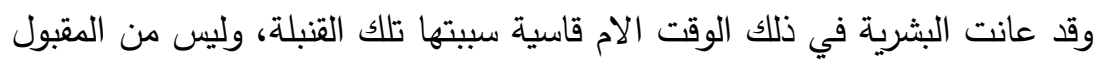
القول بان السلاح الذري يحسم المعركة بسرعة ويقلل عدد الضحايا من العسكريين

$$
\text { (r^) }
$$

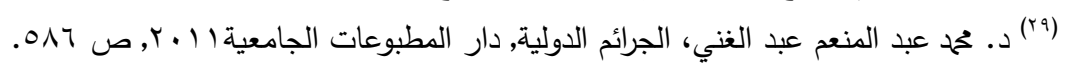

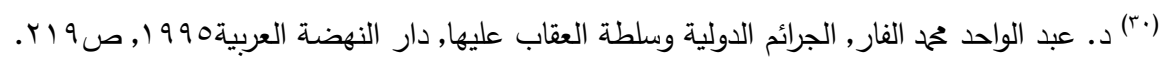

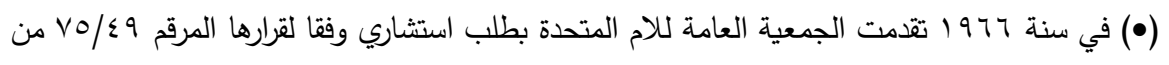
محكمة العدل الدولية حول مدى مشروعية التهديد باستخدام الاسلحة النووية او استخدامها في جميع الاحوال, وكان راي المحكمة الدولية على حق الدول النووية في التهديد بالاسلحة النووية اواستخدامها

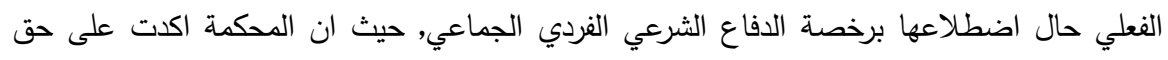

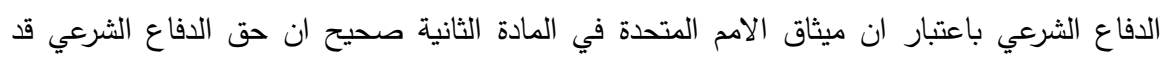
تضمنته احكام الفصل السابع من ميثاق الامم المتحدة, الا ان اعطاء هذه الرخصة بموجب الراي الاستشاري قد تعرض الى انتقادات واسعة, حيث كان الطابع النسبي للقانون الدولي الانساني وليس المطلق. انظر بهذا الصدد د. مفيد شهاب, دراسات في القانون الدولي الإنساني، دار المستقبل

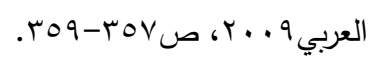

\section{( rvos $)$}


الباحث/ محمود صالح عاتي

والمدنيين(r) رغم انه يؤدي الى فناء البشرية, ومنذ تلك الحادثة اولى المجتمع الدولي

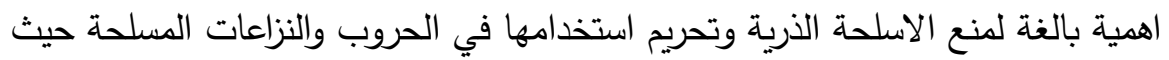

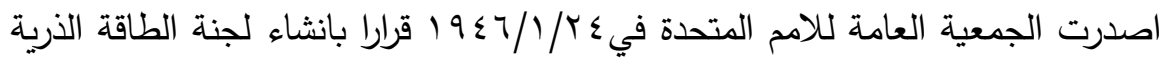
التابعة لها ووضع الاقتراحات الخاصة بتبادل المعلومات الخاصة باستخدام الطاقة الذرية

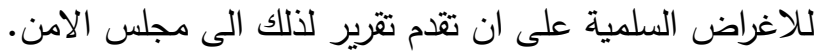

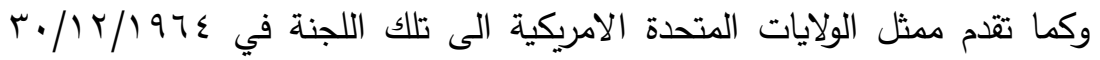

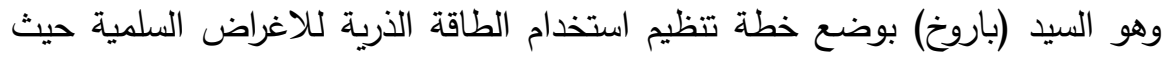
نظمت اقتراحا بانشاء هيئة دولية واجبها وضع التدابير الفعالة نحو الاشراف والرقابة والتنظيم السلمي للطاقة الذرية، حيث اعتبر انتاج واستخدام السلاح الذري، دوليه والعمل على التى

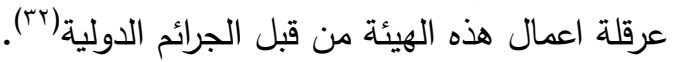
وقد بذل المجتمع الدولي جهود حثيثة من اجل استخدام الطاقة الذرية للاغراض

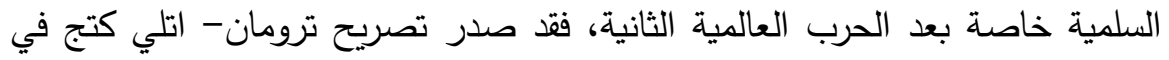

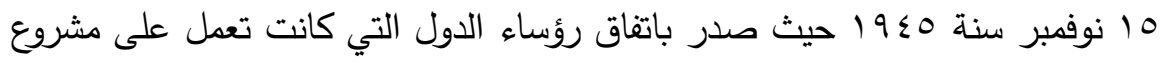
تنظيم استخدام الطاقة الذرية للاغراض السلمية, والذي اكد هذا التصريح على تلى تحريح

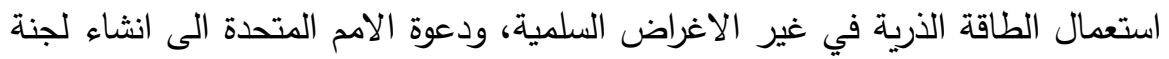

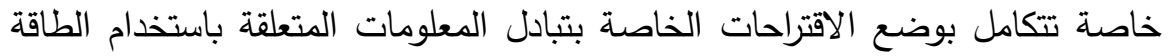

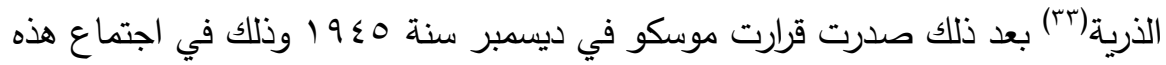

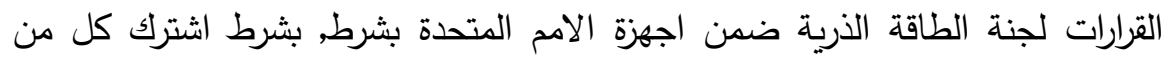

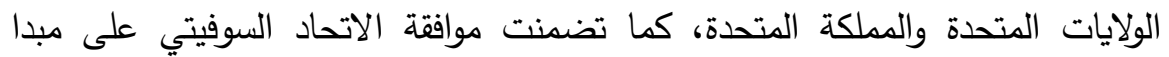

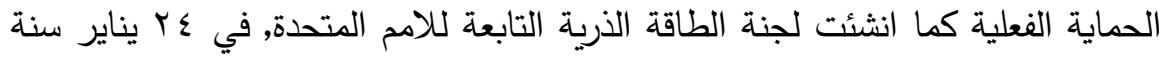
19 19 حيث اصدرت الجمعية العامة للامم المتحدة قرارا بانشاء هذه اللجنة ومهمة

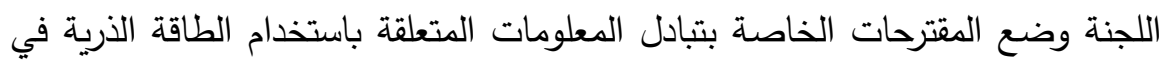
الاغراض السليمة والاشراف على اي نشاط ذري للتاكد من استخدامه للاغراض السليمة

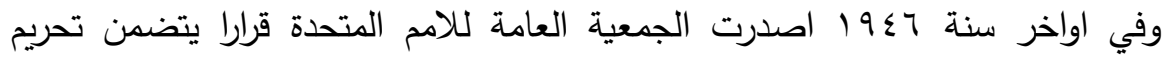
استعمال الاسلحة التي تؤدي الى تدمير على نطاق واسع، ثم انشات الولايات المتحدة

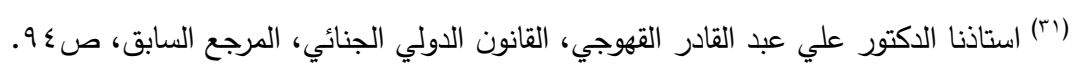

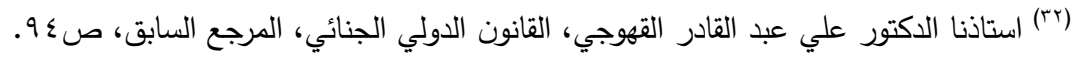

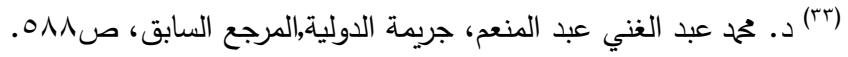

$$
(r v o s)
$$


الامريكية لجنة الطاقة الذرية للقيام بالدراسات اللازمة من اجل استخدامها للاغراض السلمية (اء؟).

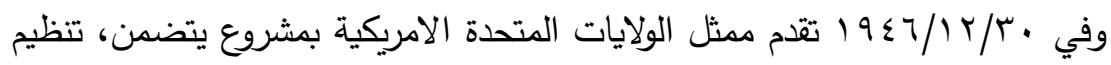

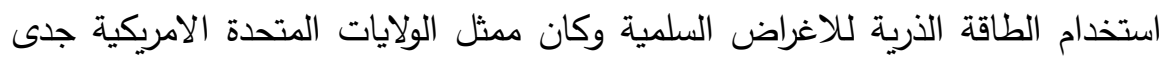

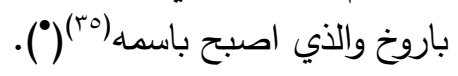

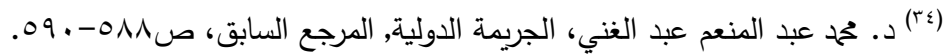

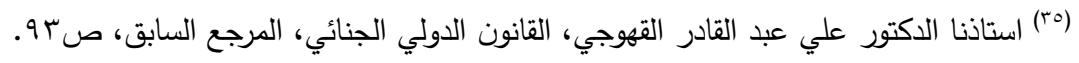

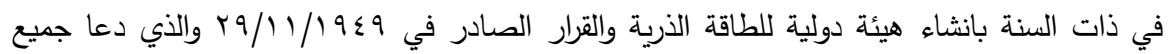

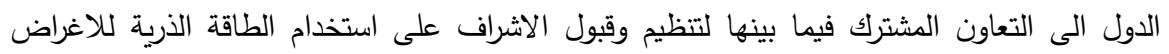

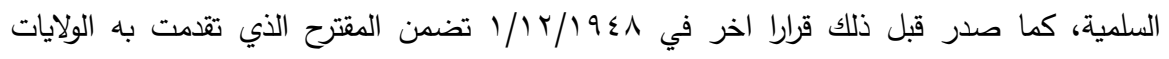

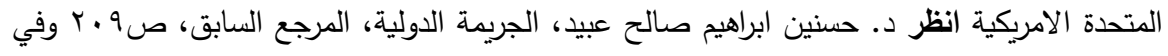

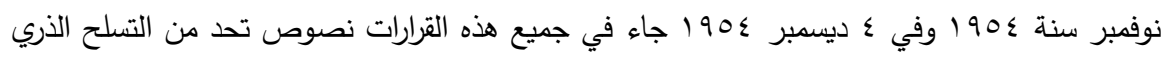

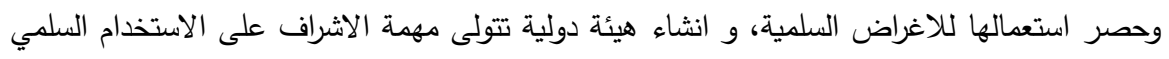

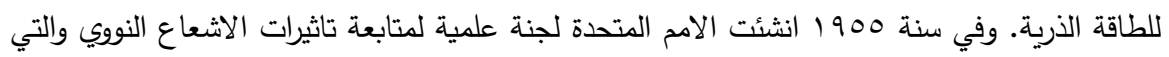

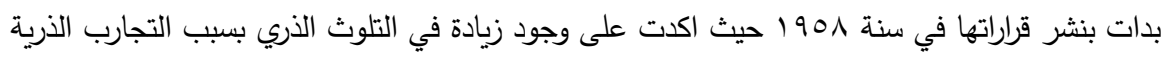
على سطح الارض.. انظر استاذنا الدكتور علي القهوجي، القانون الدولي الجنائي، مرجع سابق،

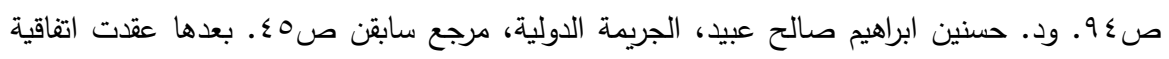

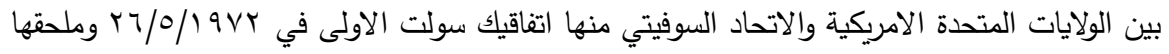

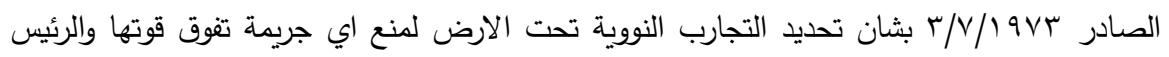

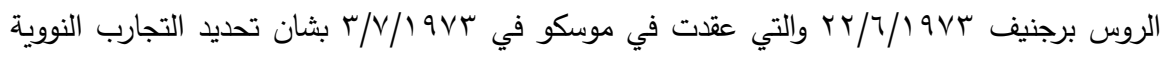

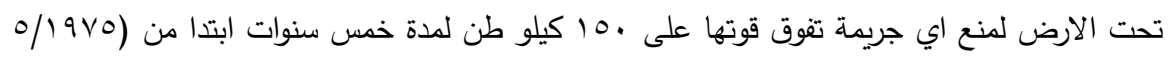

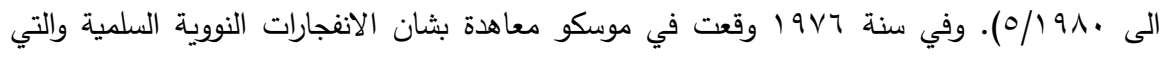

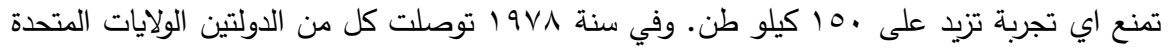

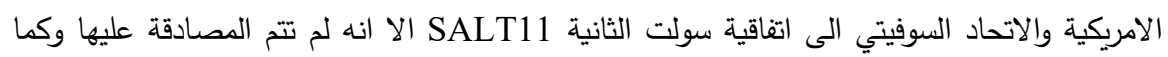

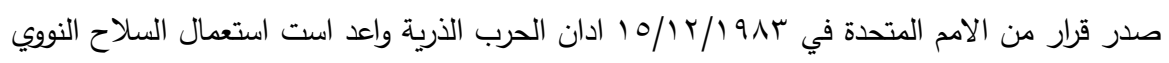

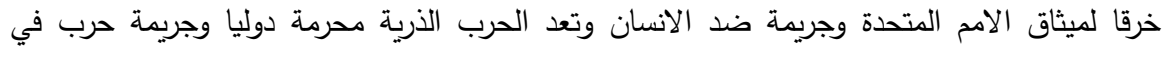

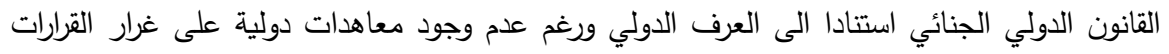

\section{( rvor $)$}


الباحث/ محمود صالح عاتي

وفي سنة باج1 وقعت الولايات المتحدة والاتحاد السوفيتي اتفاقا وكان ذلك بحضور امين عام الامم المتحدة لحضر الاستخدام الجزئي للتجارب الذرية وقت السلح

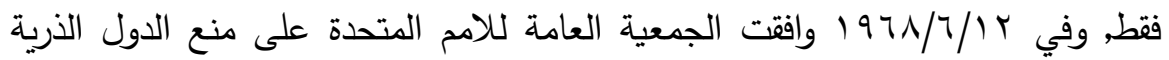
بمقتضى هذه المعاهدة, عن تقديم اية مساعدة مباشرة او غير مباشرة للدول الاخرى

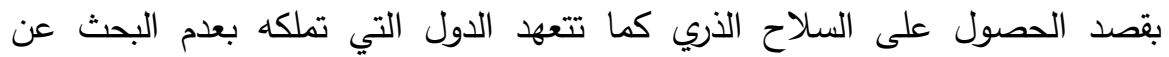

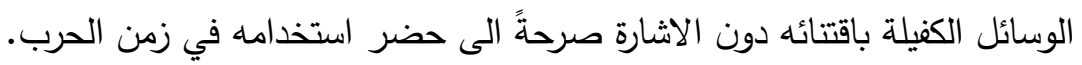

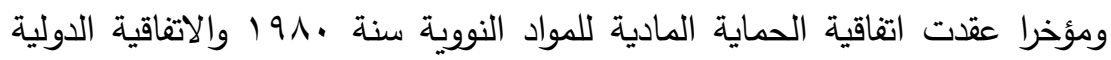

$$
\text { لقمع اعمال الارهاب النووي سنة } 999 \text { 19. }
$$

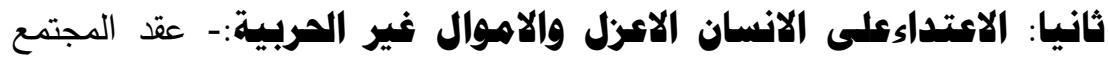

الدولي عدة اتفاقيات لحماية الاسرى والجرحى والمرضى وفي مقدمتها كانت اتفاقية سنة

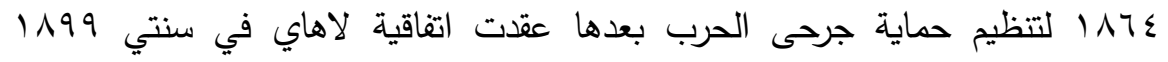
و 19.9 والتي اطلق عليها قانون لاهاي بعدها اصبح هنالك تطور كبير في قوانين

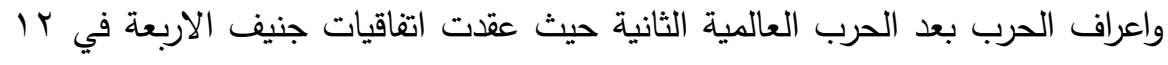
اب 99 أوقد نظمت الاتفاقيات الاولى احكام لحماية والجرحى والمرضى العسكريين

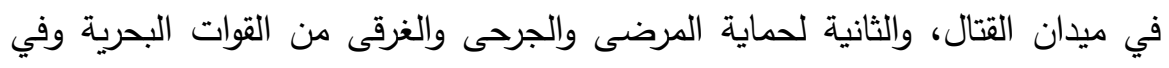

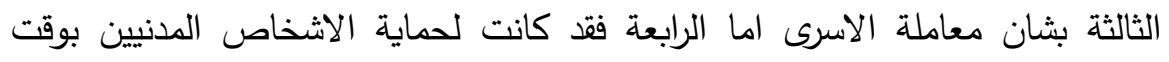

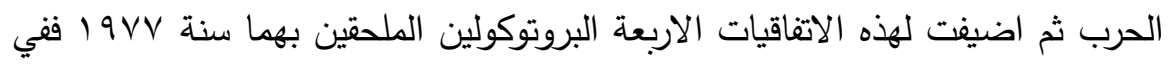
البروتوكول الاول لحماية ومساعدة الجرحى والمرضى من العسكريين او المدنيين وكما

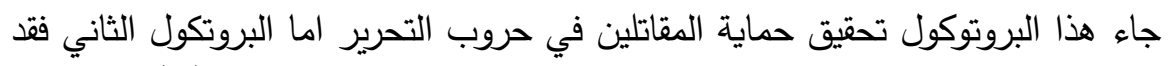

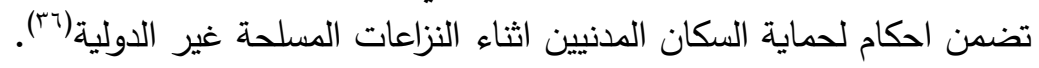
وقد اعتبرت الاتفاقيات والمواثيق الدولية هذه الافعال، تعد خروجا على الألئ العمال

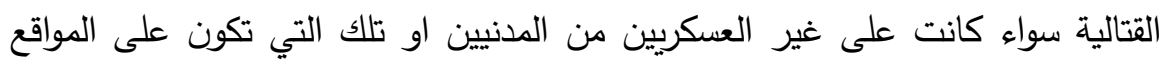

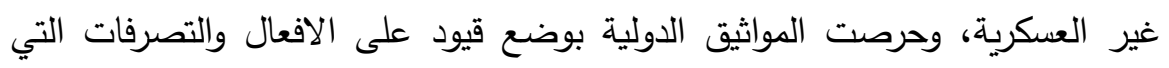

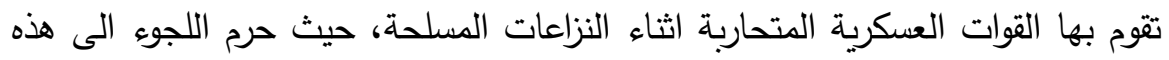

الصادرة من الامم المتحدة فاستعمال السلاح الذري جريمة حرب الاسلحة الكيمياوية والجرثومية كان بموجب العرف الدولي نظرا لاثاره الخطيرة.

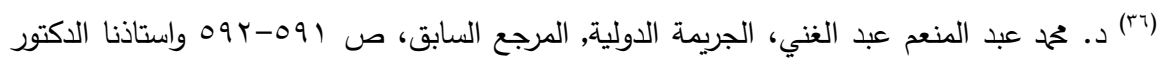

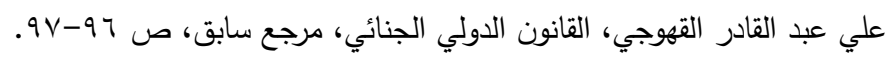


الافعال من خلال العرف الدولي الذي ما زال يتمتع بالصدارة بين مصادر القانون الدولي

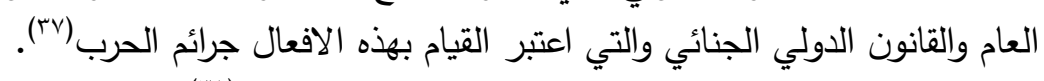

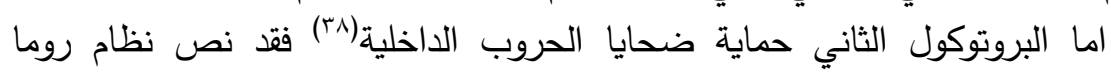

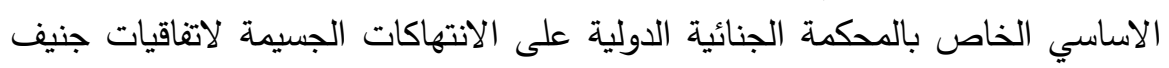

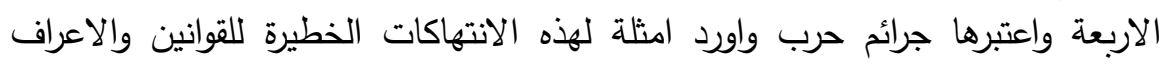

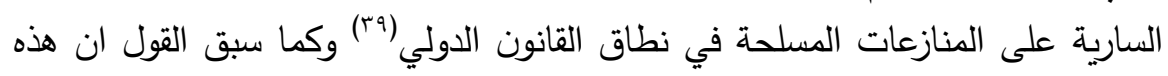
الافعال قد تقع اثناء القتال حيث, يحرم على المتحاربين القيام بها بهذه الافعال الفال الثاء الثاء

سير القتال كا الاعتداء على المدنيين حيث تتضمن هذه الجرائم الافعال الاتية:-(.؛).

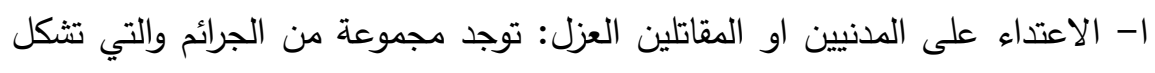
اعتداء على الاشخاص مدنيين اوعسكريين او على الاموال مثل مهاجمة المدنيين

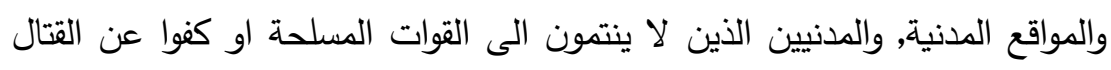

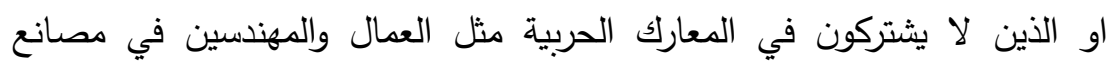
الذخيرة، حيث يعتبرون من القوات المساعدة للقوات المسلحة.

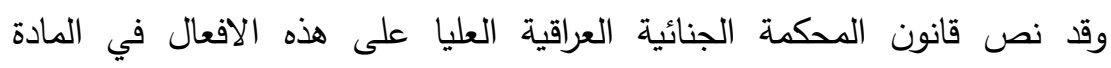

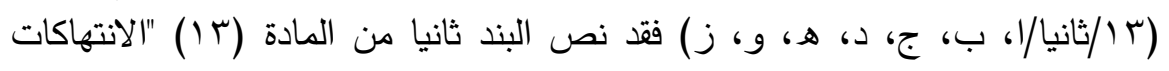

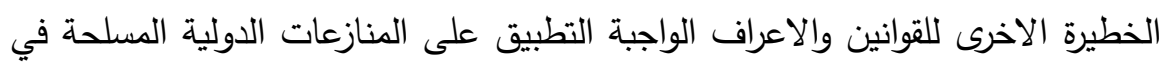
النطاق الثابت للقانون الدولي وبالتحديد اي فعل من الافعال الاتية:

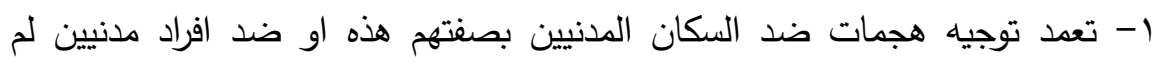

$$
\text { يشاركوا مباشرة في الاعمال الحربية. }
$$

r- تعد توجيه هجمات ضد اهداف مدنية بضمنها مواقع لا تشكل اهداف عسكرية.

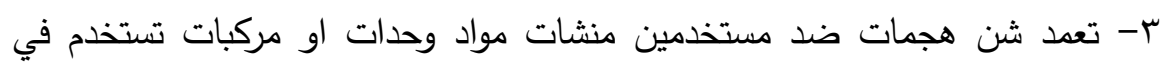
مهام المساعدم الانسانية او حفظ السلام طبقا لميثاق الامم المتحدة، طالما كانت

صرد) استاذنا الدكتور علي عبد القادر القهوجي، القانون الدولي، القانون الدولي الجنائي، مرجع سابق،

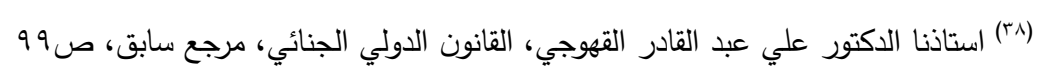

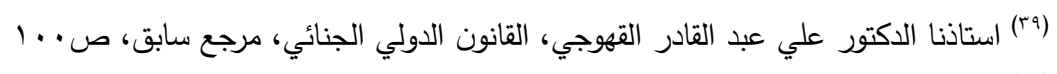

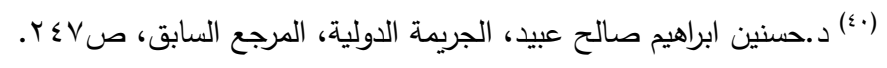

$$
(\operatorname{rvos})
$$




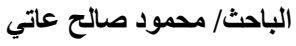

مثل هذه المهام تستحق الحماية الممنوحة للمدنيين او الاهداف المدنية بموجب قانون المنازعات المسلحة.

ع - تعد شن هجوم مع العلم بكون هذا الهجوم سيسفر عن خسائر تبعية في الارواح او عن اصابات بين المدنيين او عن الحاق اضرار مدنية يكون افراطا واضحا بالقياس الى مجمل للمكاسب العسكرية المتوقعة الملموسة والمباشرة. 0- تعد شن هجوم مع العلم ان هذا الهجوم سيسفر عن احداث ضرر واسع النطاق

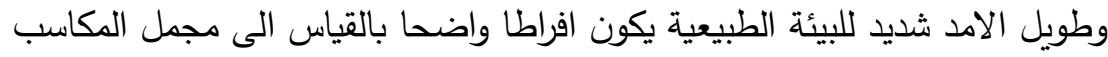

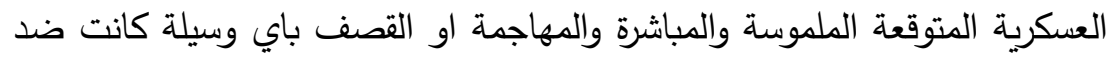

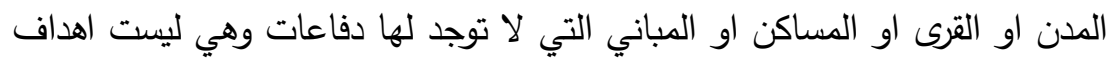
عسكرية. T- قتل او جرح مقاتل كان قد تخلى عن سلاحة او انه لم يعد يمتلك وسائل الدفاع عن نفسه واستسلم بشكل واضح". من النص المتقدم يتضح ان هنالك مجموعة من الافعال يحرم القيام بها وتعد جرائم

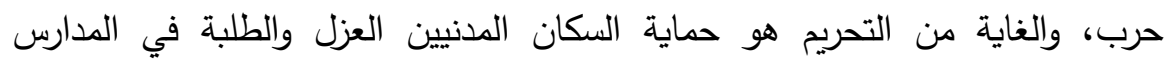

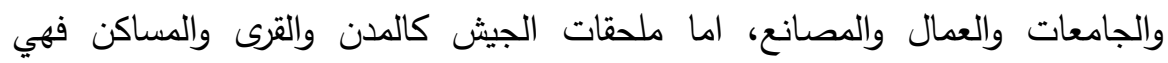
مشمولة بالحضر ايضا وكما حضرت الفقرة (ي) من ذات النص الص على تعدد توجيه هجمات لا تثكل اهداف عسكرية مثل دور العبادة, والمدارس والجامعات والمستشفيات

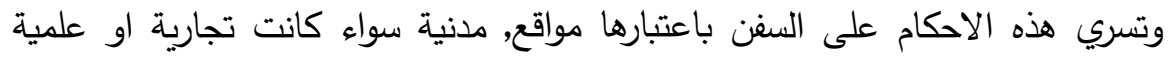

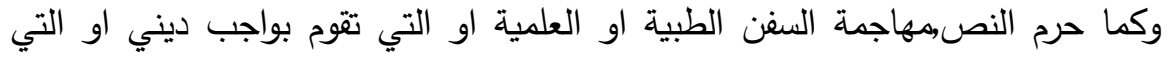

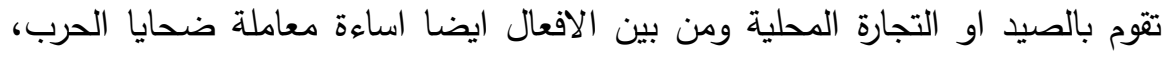

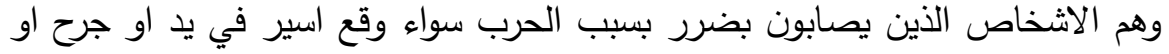

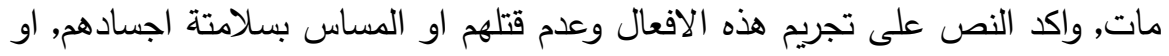

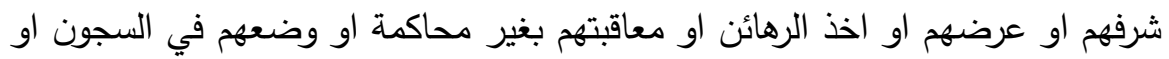

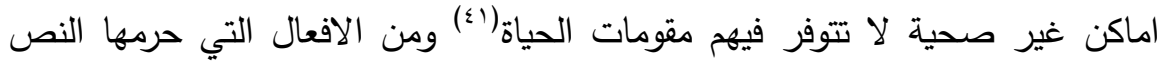
السالف الذكر وعدها جرائم حرب ايضا(זی):-

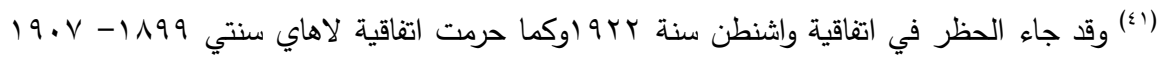

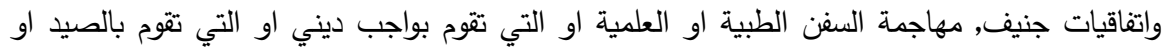
التجارة المحلية (1) ومن بين الافعال ايضا اساءة معاملة ضحايا الحرب وهم الاشخاص الذين يصابون

\section{( $r v \circ q$ )}


ا- القتل المقصود:- تعد جريمة القتل العمد اكثر الافعال وقوعا في جرائم الحرب سواء وقعت في بسلوك ايجابي اوسلبي حيث نصت الماده (T) (I) من اتفاقيات

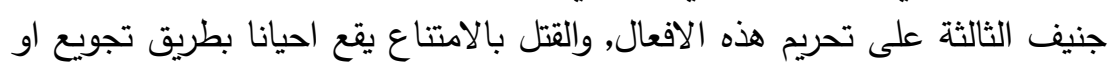
منع الطعام.

ب- التعذيب:- وهو تعرض جسد الا نسان الى الالام شديدة, وقد يكون ماديا او معنويا يحدث للضغط على الثخص بغية الحصول على اعتى اعترافات عن الاسرار

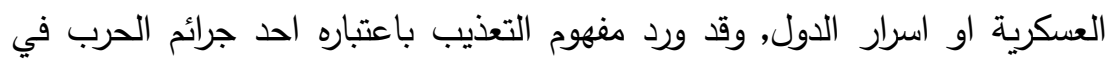
اتفاقيات جنيف وهو اخضاع الشخص لالام جسدية او نفسية بقصد الحصول منه

بضرر بسبب الحرب سواء وقع اسيرا في يد الاعداء او مات او جرح حيث اكد اتفاقية جنيف الثالثة

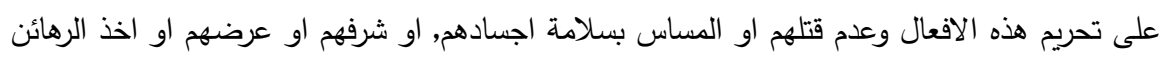

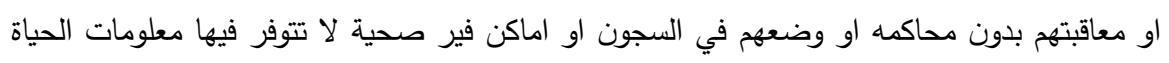

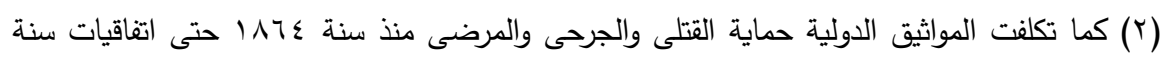

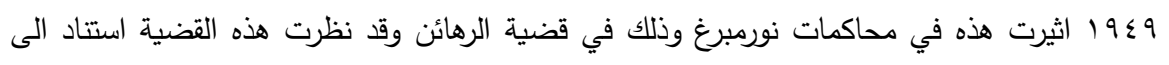

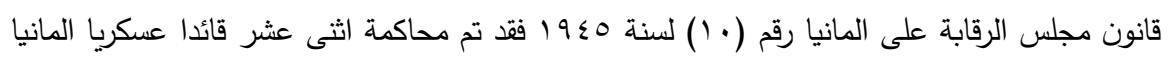

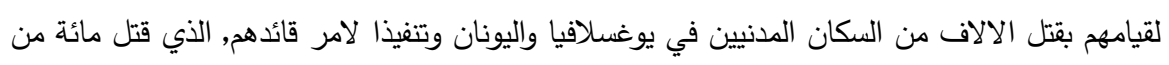

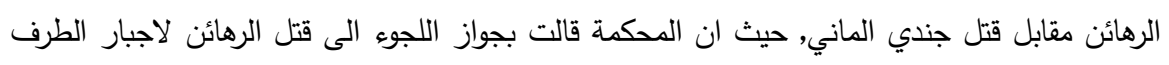

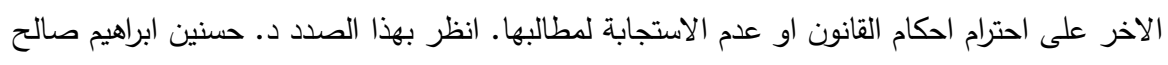

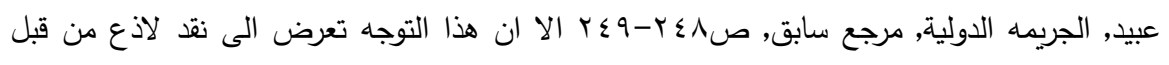

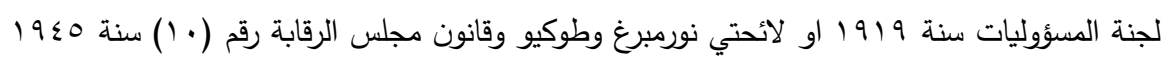

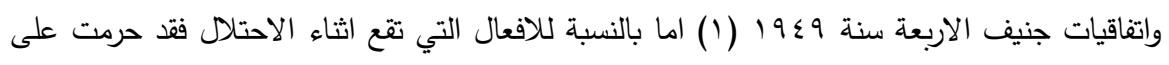

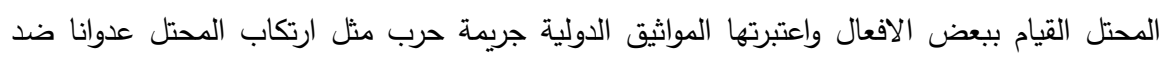

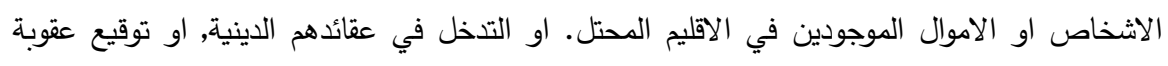

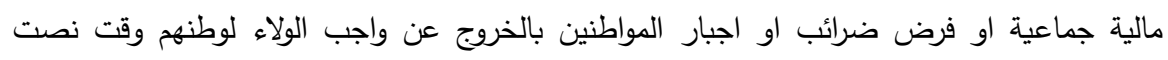

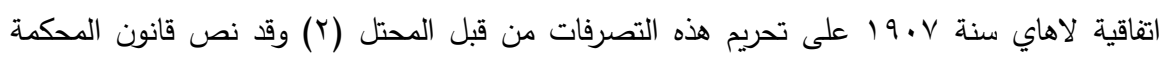

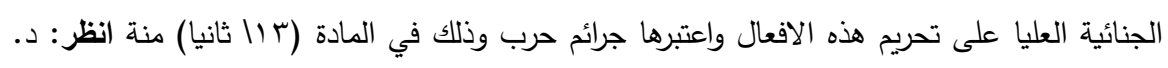

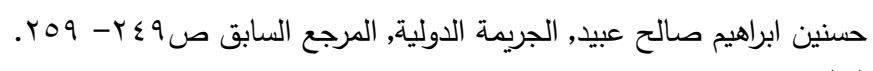

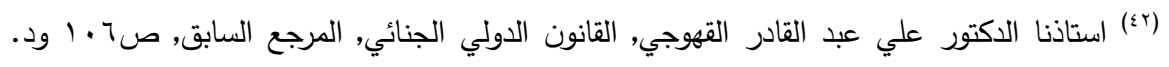

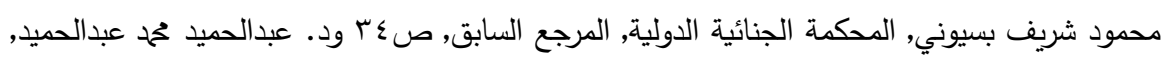

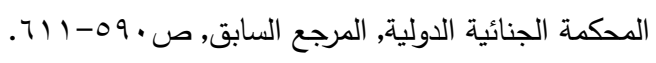

\section{(}


الباحث/ محمود صالح عاتي

على اعترافات او معلومات تتعلق بجيشه, وقد جاء في قانون المحكمة الجنائية العليا

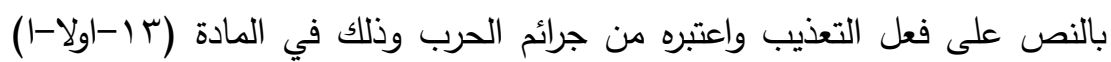

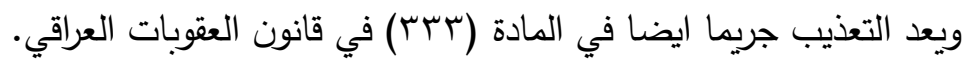
ج- المعاملة اللانسانية:- وهي الافعال التي ترتكب للحط من قيمة الانسان او كرامته كحرمانه من الاتصال بالعالم الخارجي او باهله او تقديم الطعام اليه بصورة غئه لائقة او حرمانه من النوم.

وقد نص قانون المحكمة الجنائية العراقية العليا على تحريم هذا الفعل واعده جريمة حرب اذا وقع في وقت النزاعات المسلحة التي وردت باتفاقيات جنيف الاربعة والنظام

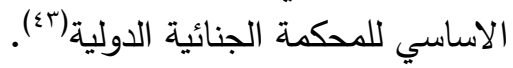

د- التجارب الطبية البايولوجية:- وهي استخدام الاسرى في حقل للتجارب لمعرفة

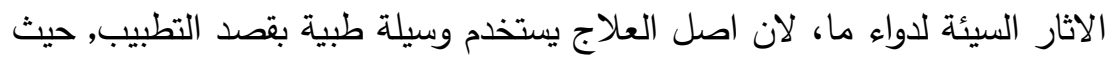

$$
\text { وردت هذه الجريمة با تفاقيات جنيف الاربعة. }
$$

هـ- فرض الام جسيمة بصورة مقصودة:- وهي تعريض الاسرة الى الالام شديدة دون الأن

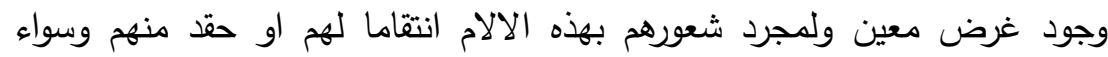

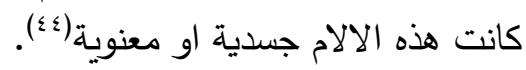
و - الاعتداءات الخطيرة على السلامة الجلسية او الصحية: الصغية - كتقديم طعام غير

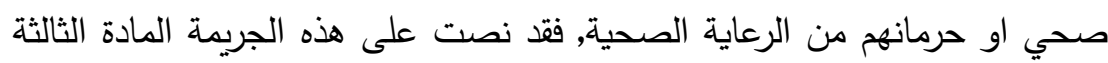

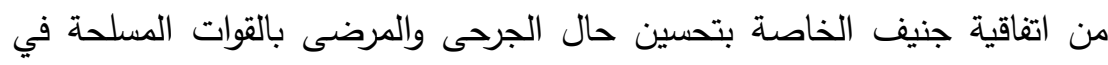
الميدان. ز - اجبار اسرى الحرب والمدنيين على الخدمة في القوات المسلحة التابعة للدولة المعادية ضد دولتهم(ب).

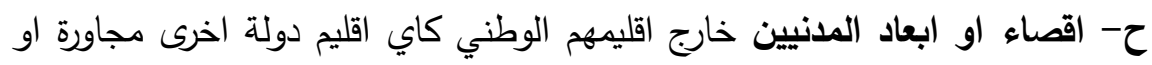

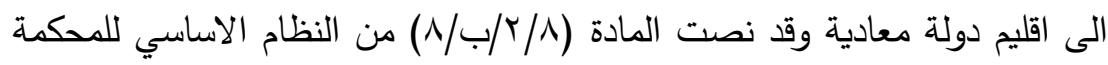

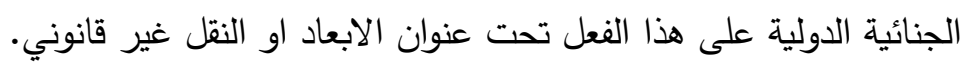

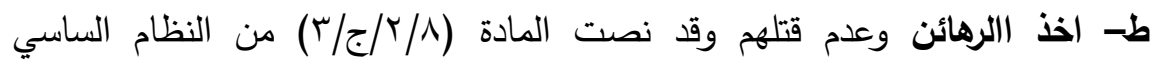
للمحكمة الجنائية الدولية واعتبر هذا الفعل من جرائم الحرب.

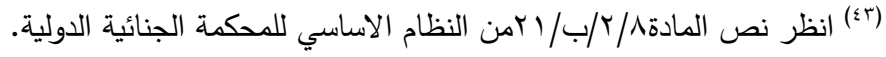

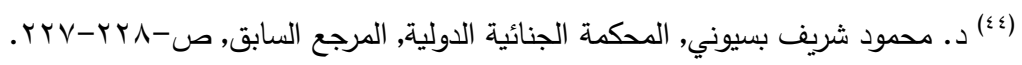


ي - عقاب بدون محاكمة وقد نصت المادة (////ج) على حرمان الاسير من محاكمة

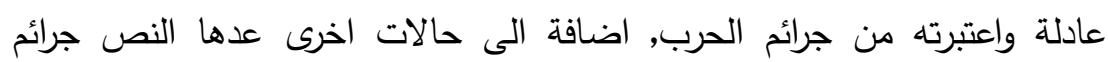

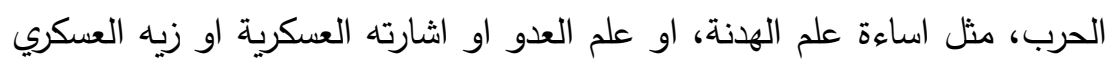

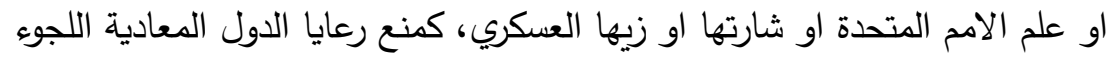

\section{الفرع الثاني

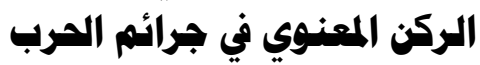

يتكون من مجموعة من العناصر الداخلية او الثخصية ذات مضمون الترون النساني والتي ترتبط بالواقعة المادية, اي اتجاه غير المشروع للادراك والارادة الحرة نحو الواقعة الإنة الاجرامية فالارادة الاثمة هي جوهر الخطا الذي هو اسلية العاس المسؤولية الجنائية في

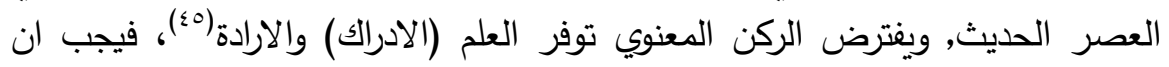

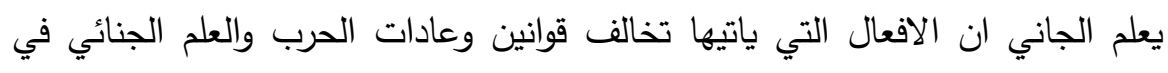
العرف والمعاهدات والمواثيق الدولية فاذا انتفى القصد الجنائي، يجب عليه ان يثبت عدم علمه بالعرف الدولي الذي يحرمه.

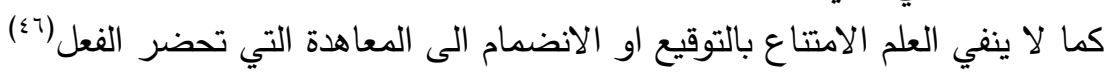

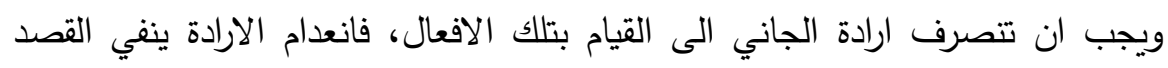

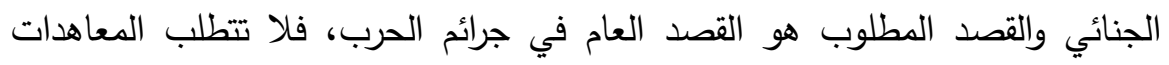
والمواثيق الدولية نية خاصة بذلك, لان ارتكاب هذه الجريمة يترتب عليه زعزعة الامن

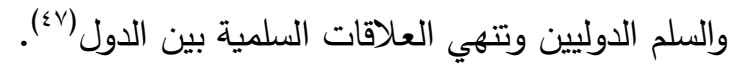

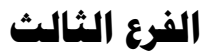

\section{الركن الدولي في جرائم الحرب التباء}

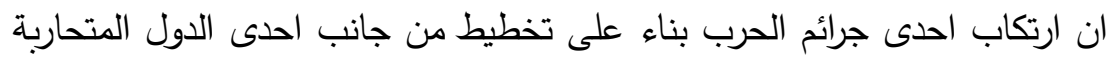

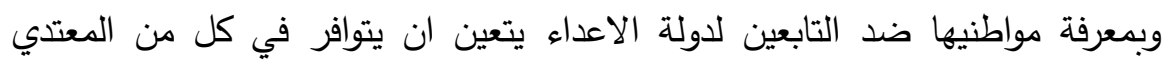

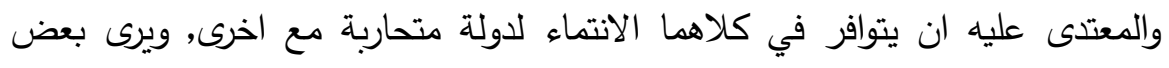

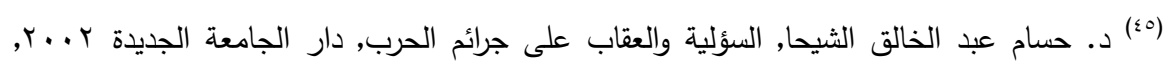

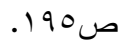

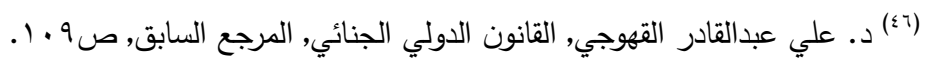

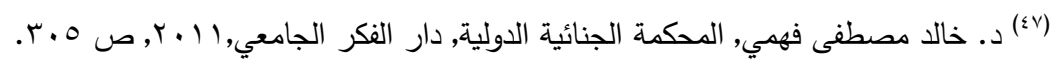

\section{$(\operatorname{rvar})$}


الفقهاء ان الركن الدولي في جرائم الحرب, هو ارتكاب هذه الجرائم بناءً على تخطيط من

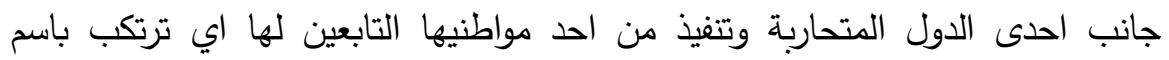

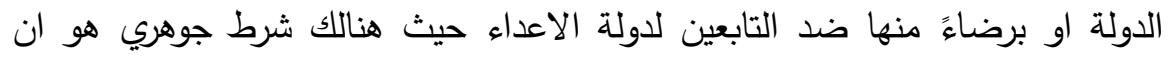

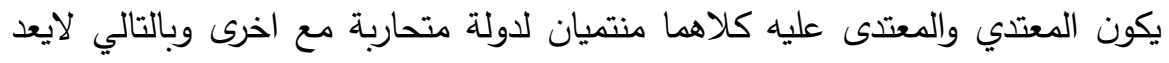

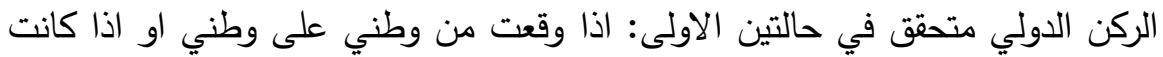

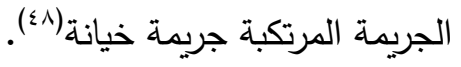

الا ان المواثيق الدولية ومنها اتفاقيات جنيف الاربعة اعطت للمجموعات المقاتلة

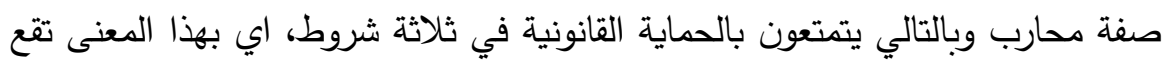

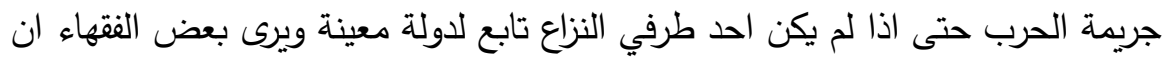

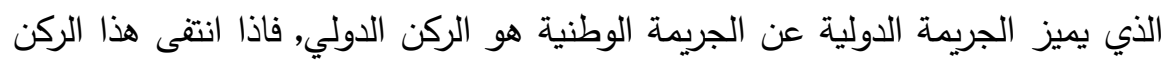

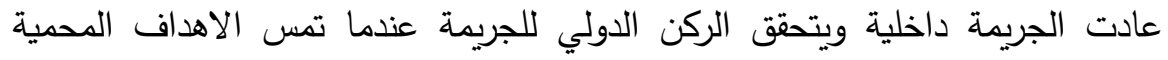
دوليا وتكتسب الصفة الدولية بمجرد ترويع الضمير العالمي ولكي تتحقق الصفة لإنة

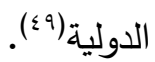

في الجريمة لا بد ان يكون الفعل او الامتتاع يمس مصالح, او قيم المجتمع الدولي

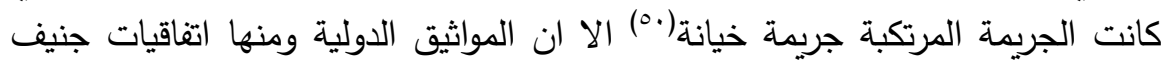
الاربع، اعطت المجموعات المقاتلة صفة محارب وبالتالي يتمتعون بالحماية القانونية اذا توفرت فيهم ثلاث شروط، من هذا يتضح ان جريمة الحرب تقع حتى اذا لم يكن احد

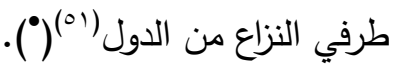

(ㅅ)

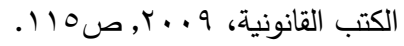
(99) يحيى عبدالله طعيمان, جرائم الحرب في نظام المحكمة الجنائية الدولية, مكتبة خالد بن الوليد

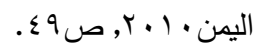

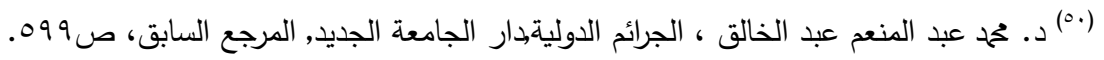

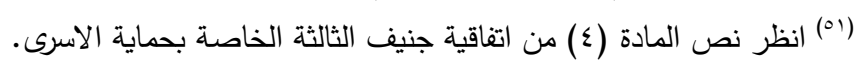

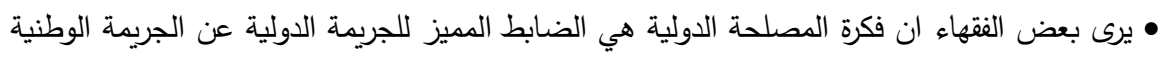

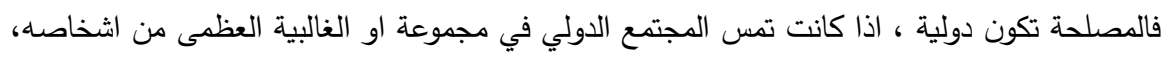

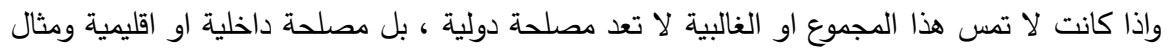

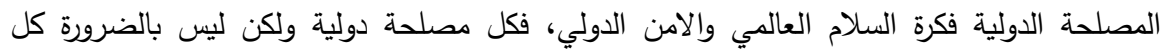

\section{( $\operatorname{rvqu})$}




\section{الاطباب الثاني

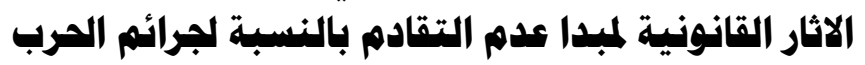

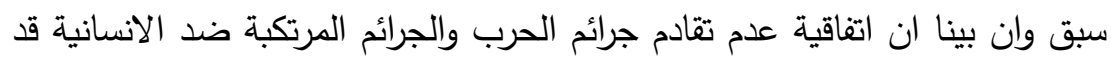

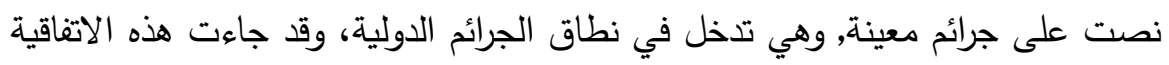
باحكام فرضت فيها التزامات على الدول الاطراف باعتبار ان الجهود الدولية هدفها دائما الى مكافحة الجرائم الدولية لاشد خطورة, وذلك من خلال انزال العقاب بحق مرتكبيها لتحقيق العدالة المنشودة وعلى هذا الاساسرجاءت القواعد القانونية الدولية الجنائية

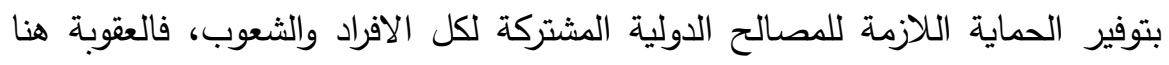

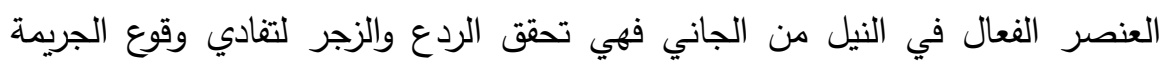

مستقبلا.

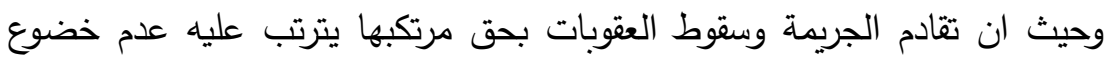

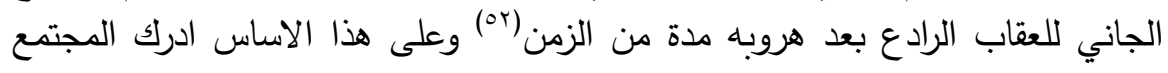

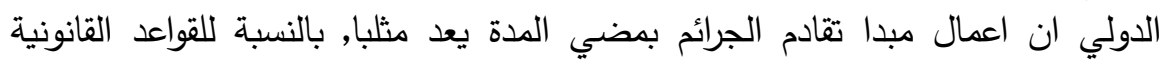
الدولية التي وضعت لمقاضاة مرتكبي الجرائم الخطيرة والتي تعد جريمة الحرب من من بينها

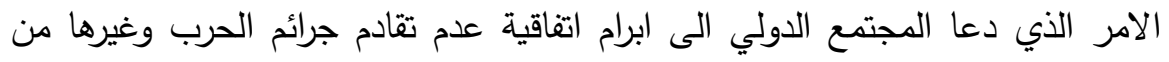

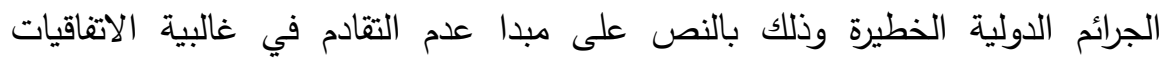

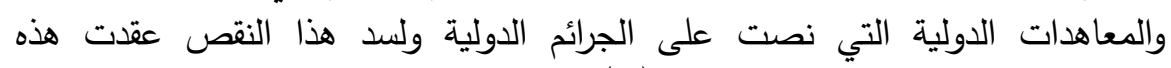

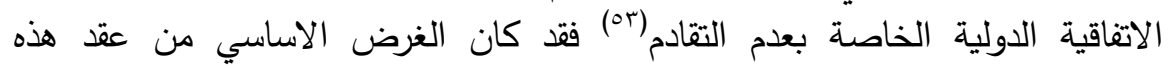

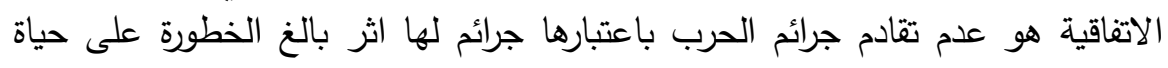

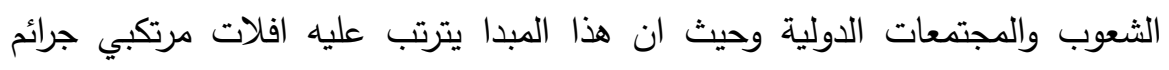

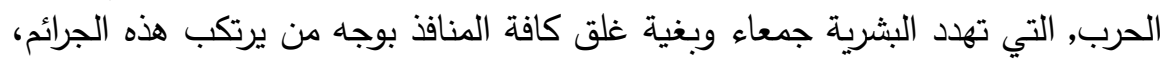

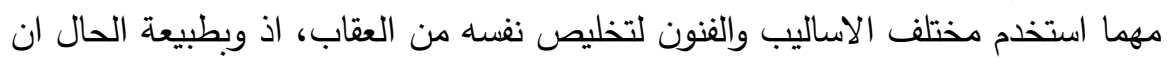

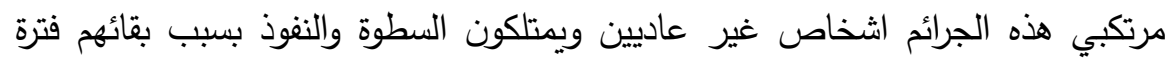

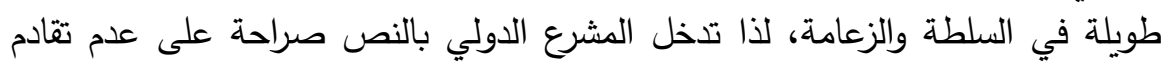

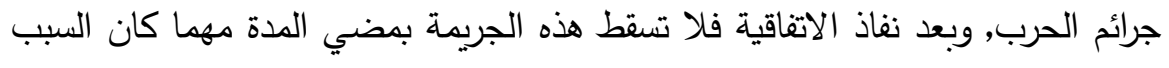

مصلحة وطنية تحقق مصلحة دولية. انظر بهذا الصدد: د. السيد ابو عطية. المحاكمات الجنائية

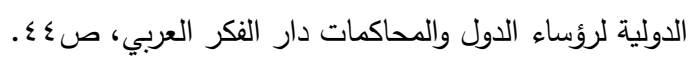

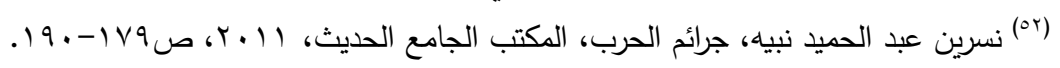

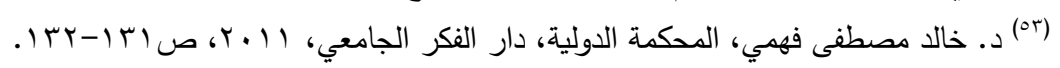


ولا يمنع من معاقبة الجاني تحت اي ظرف كان، فالوقت مفتوح امام المحاكم الجنائية

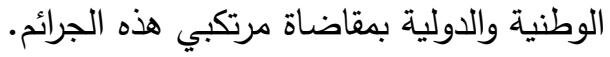

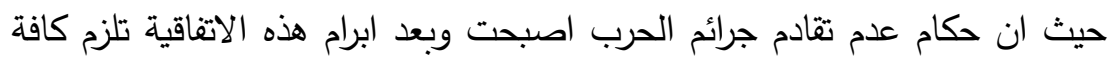
الاطراف الدولية, الذين يرومون عقد اتفاقيات تتضمن افعال تشكل جرائم دولية, وكذلك

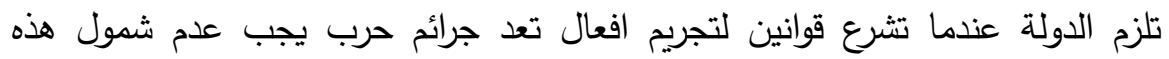

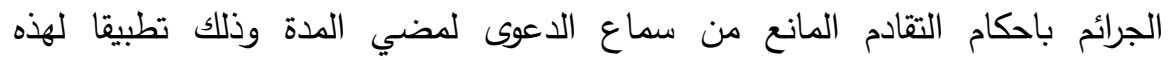
الاتفاقية(؛). وتسري احكام عدم التقادم في جرائم الحرب على ممثل الدولة والافراد الذين

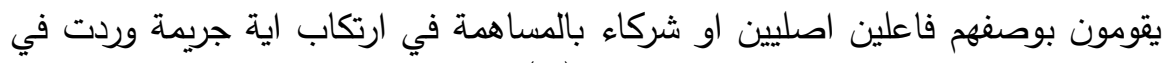
هذه الاتفاقية او بتحريض الغير على ارتكابها (00).

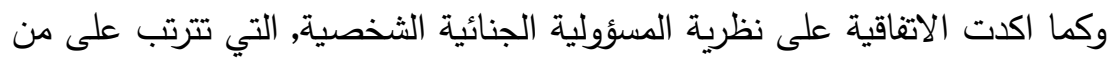

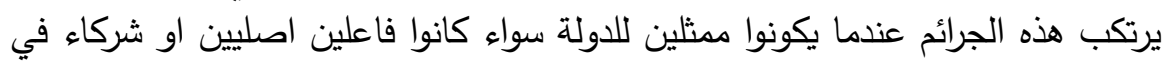

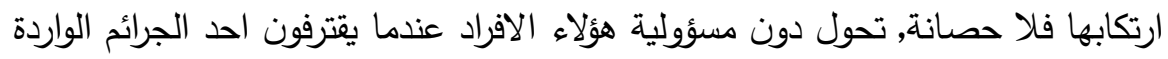

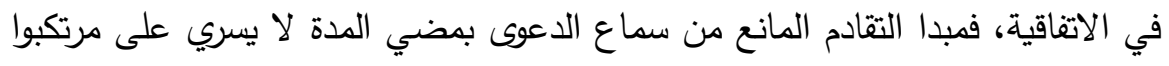

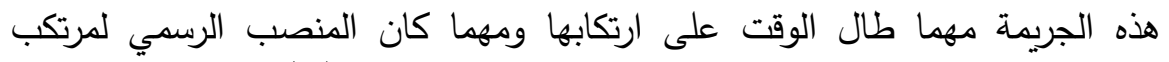

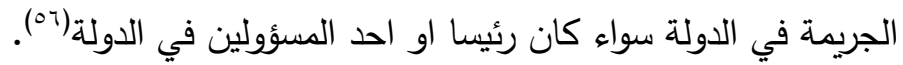

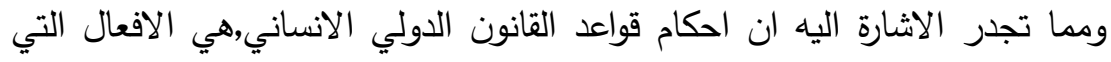

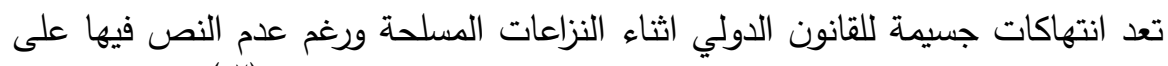

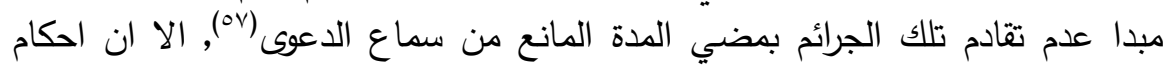

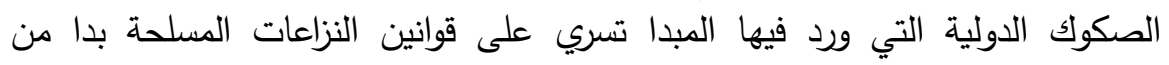

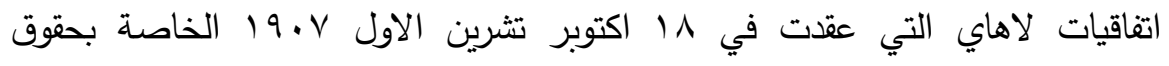

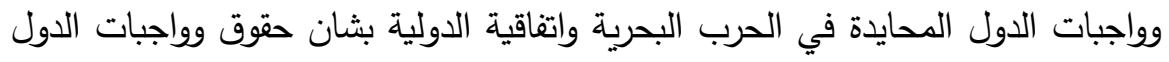

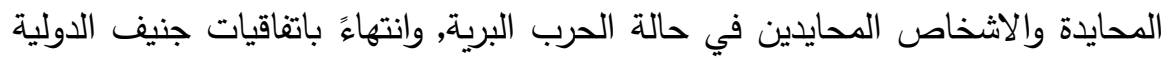

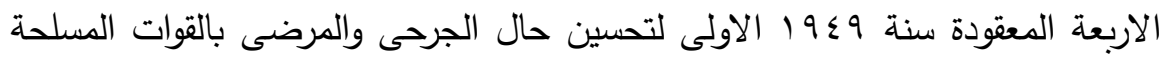

$$
\text { (ن) (نظر نص المادة (1) في اتفاقية عدم تقادم جرائم الحرب والجرائم المرتكبة ضد الإنسانية. }
$$

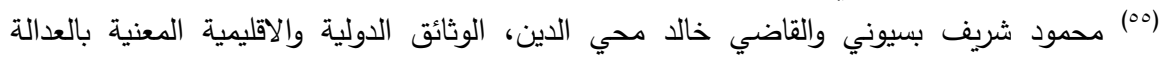

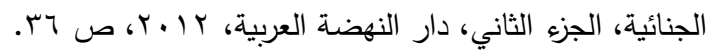

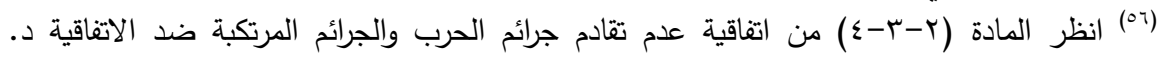

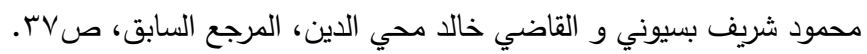

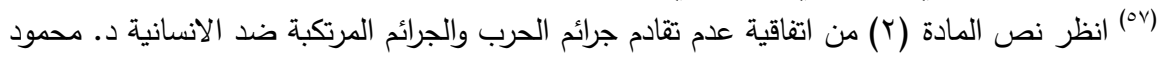

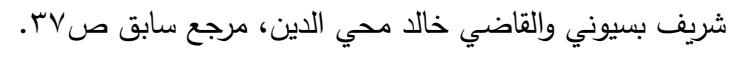

\section{( rvio $)$}




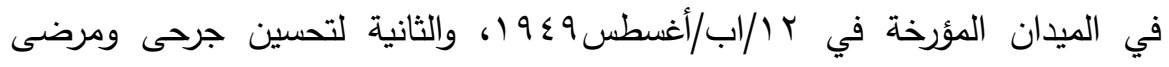
وغرقى, القوات المسلحة في البحار والمؤرخة في ب |/اب/|غسطس 9 9 أوالرابعة بشان

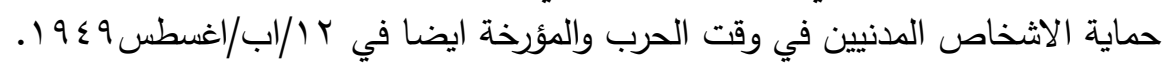
الا ان المشرع الدولي تتبه الى هذا الامر الذي عملت به الانظمة القانونية الوطنية,

فتداركه من خلال عقد اتفاقية دولية شارعة تضمنت نظاما عاما يسري على كافة الدول غير الاطراف في الاتفاقية باعتبار ان هذه القواعد اكتسبت صفتها الالزامية من انضمام غالبية الدول اليها حتى اصبحت قواعد شارعة تلزم كافة الاطراف الدولية، فكان جوهر هذه الاتفاقية هوعدم تقادم جرائم الحرب بمضي مدة من الزمن على وقوعها(ه)؛.

(^^) شريف عتلم وحمح ماهر عبد الواحد، موسوعة اتفاقيات القانون الدولي الإنساني, المرجع السابق ء؟-

• لقد ورد مبدا تقادم الجرائم المانع من سماع الدعوى الجنائية بعد مضي مدة زمنية على ارتكابها في القوانين الجنائية الوطنية, وذلك للاسباب التي تكلمنا عنها في مقدمة البحث اثناء الحديث عن الاساس القانوني للتقادم, حيث عد ذلك احد اسباب انقضاء الدعوى الجنائية, مما سبب ذلك مصدر قلق للمجتمع الدولي خشية من سريان هذا المبدا على الجرائم الاشد خطورةً التي عانت منها الثرية جمعاء, لذا بادر

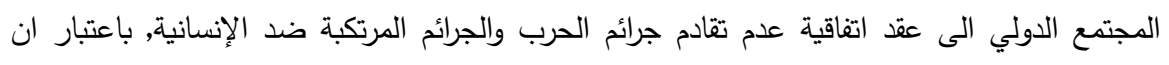
الوضع يختلف في القانون الدولي الجنائي وذلك للخصوصية التي تتميز بها الجرائم الدولي التي تعد تنتهك المصالح الدولية العليا, لاسيما الانتهاكات الجسيمة لقوانين واعراف الحرب, تلك الجرائم التي هزت لتوبي ضمير الانسانية في الحرب العالمية الثانية فقد كانت المجازر المروعة التي ارتكبت اثناء الحرب باعثا على ايقاض الضمير الانساني الدولي, في وضع القواعد القانونية الكفيلة بعدم تكرار ارتكاب مثل هذه المجازر الوحشية فقد كانت اتفاقية عدم التقادم احد المسائل التي تصدى بها المجتمع الدولي لمرتكبي الجرائم الدوليةللحيلولة دون افلات مرتكبيها من العقاب تحت ذريعة سقوط الجريمة بالتقادمبولم تكتفي الاتفاقية في النص علو مبدا عدم التقادم بل جاءت باحكام تلزم الدول الاطراف باتخاذ تدابير تشريعية

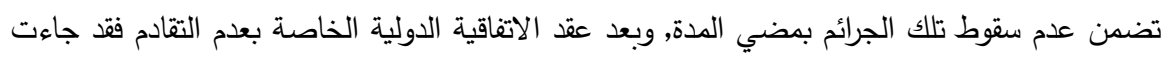
الانظمة الاساسية للمحاكم الجنائية الدولية متضمنة لمبدى عدم تقادم الجرائم الواردة فيها نظرا لخطورتهارحتى اصبح عدم تقادم الجرائم الدولية من المبادىء الاساسية للقانون الدولي الذي جعل ورود هذا المبدا في كافة المعاهدات والمواثيق الدولية التي صدرت لاحقا, والذي جاء الامر مع استقرار مبدا دولي اخر والذي اعتبر النقطة الجدلية التي انطلق منها بحثا الا وهو عدم جواز تمسك الدول بقوانينها الداخلية للتخلص من التزاماتها الدولية.

\section{$(\operatorname{rvq})$}


الباحث/ محمود صالح عاتي

\section{الخاتمة}

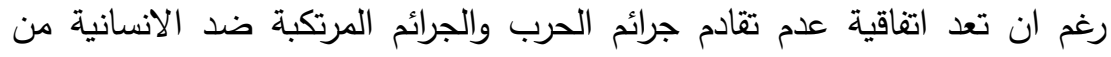

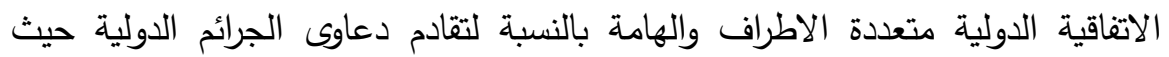

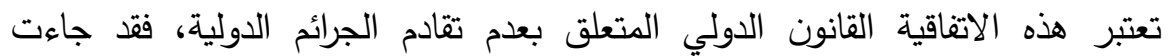

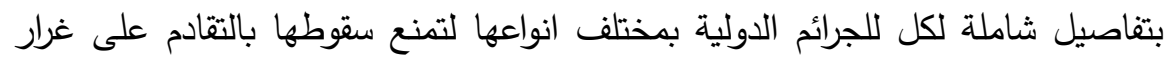

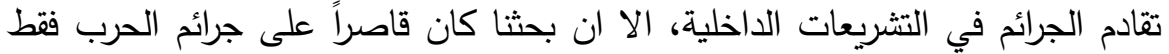

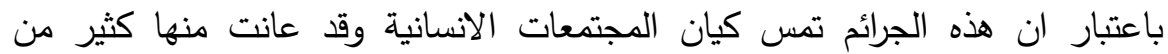

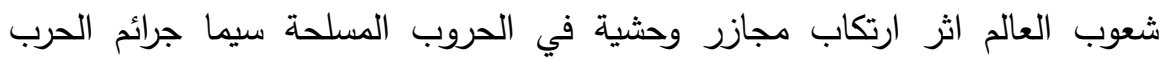

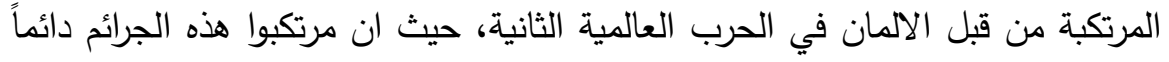

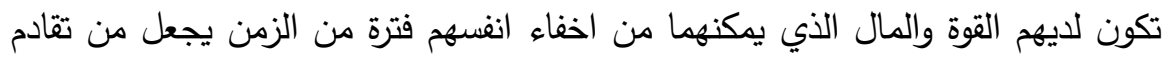

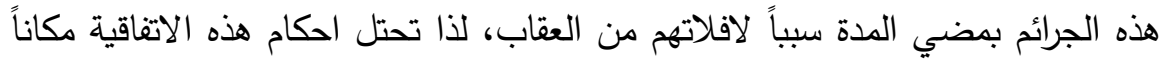

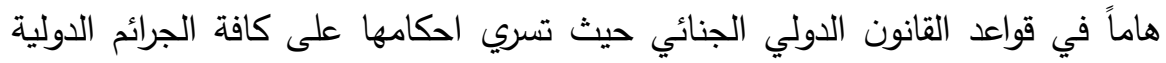

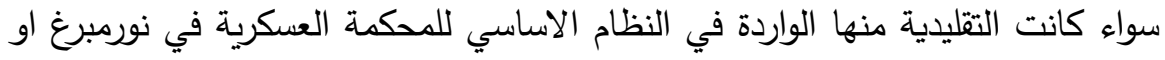

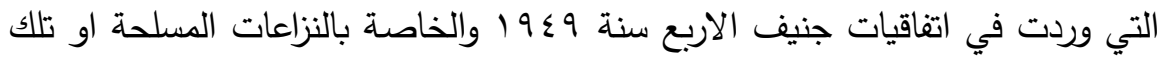

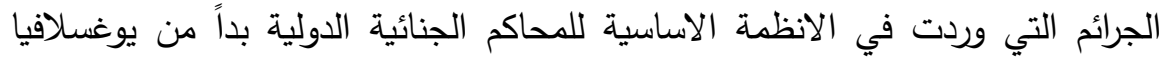
وراوندا والمحاكم المختلطة في سيراليون وتيمور الشرقية وكمبوديا وانتهاءً الجرائم الواردة في النظام الاساسي للمحكمة الجنائية الدولية.

\section{المراجع}

د. السيد ابو عطية. الدحاكمات الجنائية الدولية لرؤساء الدول والمحاكمات دار الفكر العربي.

- د. حازم محمد عتلم في مؤلفه الموسوم, قانون النزاعات المسلحة الدولية (rT) من الصكوك التي تتعلق بهذا الثأن.

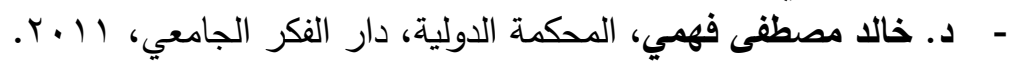

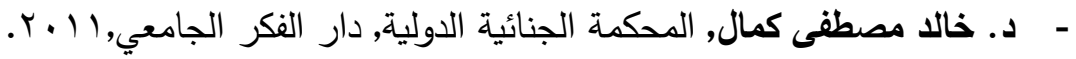

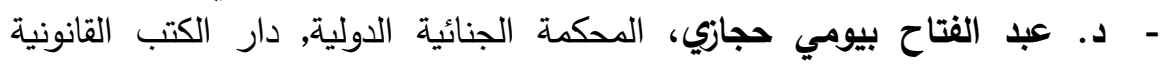
.$T \cdot I V$

- د. عبدالواحد محمه الفار, الجريمة الدولية وسلطة العقاب عليها, دار النهضة العربية 


$$
\text { - د. علي عبد القادر القهوجي، القانون الدولي الجنائي. }
$$

- د. محفوظ سيد عبد الحميد محلد، دور المحكمة الجنائية الدولية ليوغسلافية السابقة

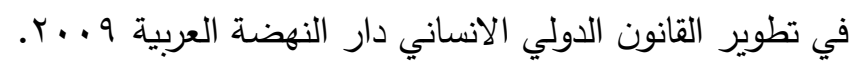

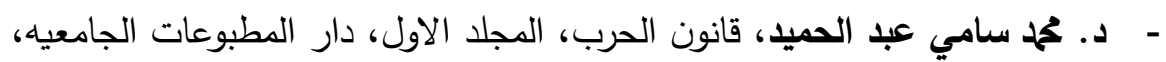
. . . V

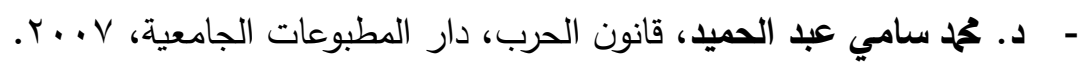

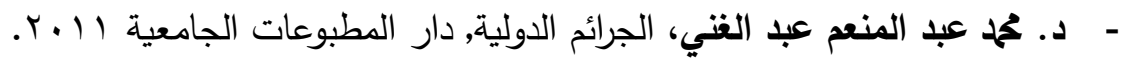

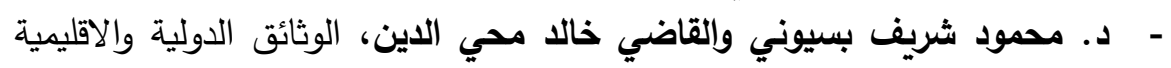

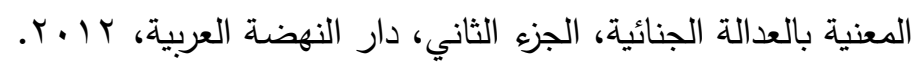

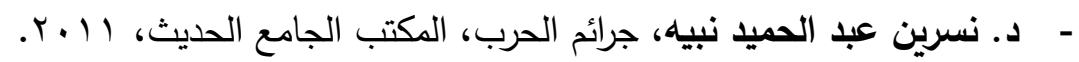

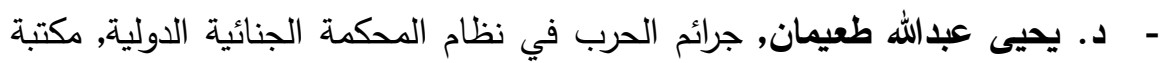

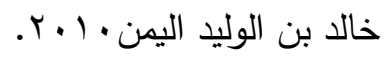

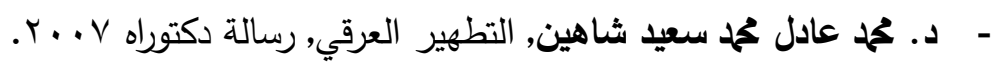

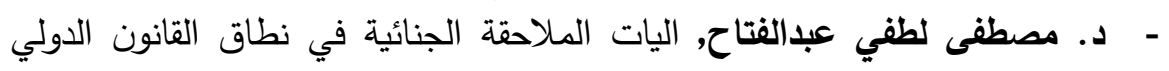

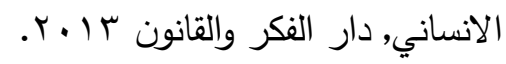

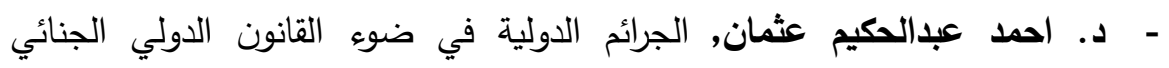

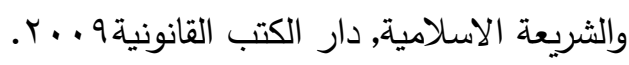

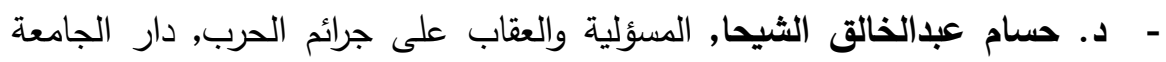

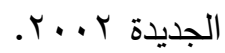

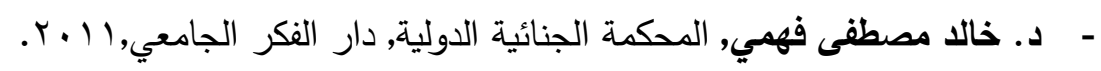

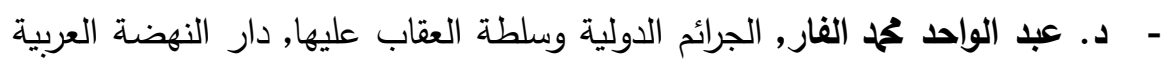

- د. عبدالحميد محمد عبدالحميد, المحكمة الجنائية الدولية, دار النهضة العربية . . . .

- د. مفيد شهاب, دراسات في القانون الدولي الإنساني، دار المستقبل العربي,9 . . r.

- Donnedieu de Vapres -LES process de nurmerge devant ies Principes du Droit international-1947.

- Pompe; aggressive war and international war London, 1954.

$$
(\operatorname{rvq})
$$

